\title{
Walking and the social life of solar charging in rural Africa
}

Nicola J. Bidwell, Masbulele Siya, Gary Marsden, William D. Tucker, M. Tshemese, N. Gaven, S. Ntlangano, Simon Robinson and Kristen Ali Eglinton

\begin{abstract}
We consider practices that sustain social and physical environments beyond those dominating sustainable HCI discourse. We describe links between walking, sociality, and using resources in a case study of community-based, solar, cellphone charging in villages in South Africa's Eastern Cape. Like 360 million rural Africans, inhabitants of these villages are poor and, like $25 \%$ and $92 \%$ of the world, respectively, do not have domestic electricity or own motor vehicles. We describe nine practices in using the charging stations we deployed. We recorded 700 people using the stations, over a year, some regularly. We suggest that the way we frame practices limits insights about them, and consider various routines in using and sharing local resources to discover relations that might also feature in charging. Specifically, walking interconnects routines in using, storing, sharing and sustaining resources, and contributes to knowing, feeling, wanting and avoiding as well as to different aspects of sociality, social order and perspectives on sustainability. Along the way, bodies acquire literacies that make certain relationalities legible. Our study shows we cannot assert what sustainable practice means a priori and, further, that detaching practices from bodies and their paths limits solutions, at least in rural Africa. Thus, we advocate a more "alongly" integrated approach to data about practices.
\end{abstract}

\section{Introduction}

HCI researchers and designers usually inhabit environments full of technologies that use electricity or fuel, but the technologies they produce affect the $25 \%$ of people globally who do not have effortless access to electricity and the $92 \%$ who do not own motor vehicles. With few exceptions [Dillahunt et al. 2009; Brynjarsdóttir and Sengers 2009; Bidwell and Browning 2010; Wyche and Murphy 2012] discussion of sustainability in HCI neglects the $50 \%$ of the world that live on less than $\$ 2.50$ a day and the $70 \%$ of the "developing" world's poor who live rurally [World Bank 2010]. In this article we expand this discussion by considering practices in a society where custom and constraints involve sharing few resources by Western norms. We describe a case study in which people in rural Africa walked to charge cellphones at two communal solar-powered Stations that we designed. By doing so, we aim to enrich meanings about sustainability and promote engaging with the ways people understand, want, avoid and make and use things to sustain social and physical environments beyond those dominating sustainable HCI. 
Users of the cellphone Charging Stations we deployed in South Africa's Eastern Cape are poor, like 360 million rural Sub-Saharan Africans [IFAD 2011], and survive using practices that, mostly, involve local physical resources and locally derived social bonds. Their circumstances differ from those of most designers who live fairly affluently in small units amidst quite diffuse social networks. Designers' understandings about comfort and convenience are also situated and normalized in the gas and electric domestic and commercial machineries, transport infrastructures and globalized food supply chains of industrial regions. These differences raise issues about designers' interventions in rural Africans' practices and about power relations between Western designers and Africans with respect to the systemic effects of practices on our planet (e.g., Birtchnell [2012]). Consider the potential implications for the "good life": [Reckwitz 2002] of an initiative in Eastern Cape conceived overseas and unrelated to our project. The scheme distributes "rocket-stoves" to reduce local forest depletion and raises funds by reselling carbon credits earned by the scheme. Consider now, how women elsewhere in Eastern Cape variously feel freedom and bonds with others and with their ancestors as they walk through the forest together gathering fuelwood, proud of the size and neatness of their woodpiles. Without access to forests, women miss these experiences and feel less of a mother and hard working adult woman [Cocks et al. 2012]. This article is not about forest depletion, carbon politics or fuelwood; but it is about practices in which walking, to access and use resources, including electricity, links together bodies, sociality, physical environments, and felt experiences.

We refer to practice, here, in both the mundane sense, such as fetching wood or charging phones, and the theoretical sense of embodied, habitualized social practices [Bourdieu 1990]. A practice consists of a routinized set of bodily activities that interconnect with certain routinized ways to understand, interpret, know how, feel, want and avoid; and certain routinized ways to make, use and describe physical and abstract things [Reckwitz 2002]. This agrees with HCI's wider turn from Cartesian mind-body dualism to the embodied knowing that we accrue and perform as we move, talk, and physically manipulate the world [Dourish 2001; Klemmer et al. 2006]. Humans embody knowledge by carrying out a practice such that qualities of the many interconnected constituents of a practice are qualities of the practice itself, not of a person participating in the practice. Thus, any individual person is both the "unique crossing point" of the many practices they perform and, at the same time, a carrier of each of these practices or an agent that exists in the performing of each practice [Reckwitz 2002].

We generate understandings about practices in using and managing Charging Stations by referring to other practices. Actually, we treat practices as the smallest unit of social analysis [Birtchnell 2012] but claim that walking links routines of knowing, doing, saying, using and describing, and intimately entwines with the sociality that reproduces these routines. Practices are the product of training the body in a certain way: when we learn a practice, we learn to be bodies in a certain way. We acquire competence coordinating walking early in life [Shove and Pantzar 2005; Ingold and Lee 2006] and our postural differences reflect our cultural histories [Ingold 2007]. Walking contributes to all the knowledge we accrue, our 
artisanal techniques, our dancing and our ways to rear children; it is, as Ingold and Lee [2006, p. 2] write, "not just what the body does; it is what a body is". Of course we do not imply that being unable to walk falls short of being fully human, but that walking perpetuates a prevalent way of being a body. Cross-national time-use studies show many relationships between walking and local factors [Levine 1997] and the ways people walk in different places illustrate that not only do we walk because we are social beings but that "we are also social beings because we walk" [Ingold and Lee 2006, p. 2].

Phenomenological insights suggest that walking features in knowing, using and feeling; but even when research specifically involves walking and closely observing practices, such as in ethnography, we are often unmindful of our own walking [Ingold and Lee 2006]. We walk half-awake and still reach the bathroom in the dark; we can walk "lost in thought", or just plain lost; we pace when anxious, we hurry when scared and trudge when unhappy. When we speak of walking in daily life we tend to classify it in practices or patterns (e.g., "walking the dog") and distinguish between genres like a "purposeful" walk to a shop for groceries or going for a "proper" walk [Ryave and Schenkein 1974]. Yet, while we may walk to relax, educate or exercise ourselves, most of our walking is incidental, buried in the minutiae of life, from walking to the kettle when we switch it on in the morning to the trash when we take it out at night.

Even less ambulatory adults take over 3,500 steps per day [Bohannon 2007]; however, discussion of movement and environmental sustainability tends to focus on transport. This does not just reflect the severe consequences of the infrastructures and meanings of automobilities and aeromobilities for sustainability, but also typifies a general absence of reflecting on walking [Oksanen-Sä relä and Timonen 2004] and more specifically ways that walking may feature in sustainability. Cresswell [2010] argues that transport studies have never prioritized real bodies moving and, indeed, it is rare to read about walking to the car in the garage in the morning with respect to sustainable mobility. Yet walking has the potential to feature in transforming many practices. Adey [2008], for instance, discusses relationships between walking, emotion and how and where passengers move about in airports. Meanwhile, in HCI, Brereton and Ghelawat [2010] found that people who used a messaging system to organize city-to-suburb car sharing often sought to walk with possible ride sharers to establish a sociable scaffold for their transport arrangements.

We do not focus, here, on how walking is discursively constituted as transport, such as its merits or morality. Rather we elaborate on how walking is involved in knowing, perceiving, feeling, wanting, and using resources to orient thinking about links between walking and sustaining social and environmental infrastructures in rural Africa. We seek to show that designing to address electricity constraints cannot merely interpret walking and electricity use in Western concepts, such as about convenience (e.g., Wyche and Murphy [2012]), but must situate walking in local social relations and local meanings in rural Africa.

We begin by introducing the rural area where we trialled the Charging Stations and our methods. Then we describe nine practices in which people participated to use the Stations,

\section{http://repository.uwc.ac.za}


and some different perspectives on these. This leads us to suggest that the way we frame practices limits insights about them and that walking, while barely featuring in our account of practices, contributes to meanings and politics about the Stations. Thus, we consider various routines in using and sharing local resources to uncover relations that might also arise in charging phones. We conclude by drawing on these relations to consider how walking affected meanings about the Stations and their implications for sustainable electricity in rural Africa.

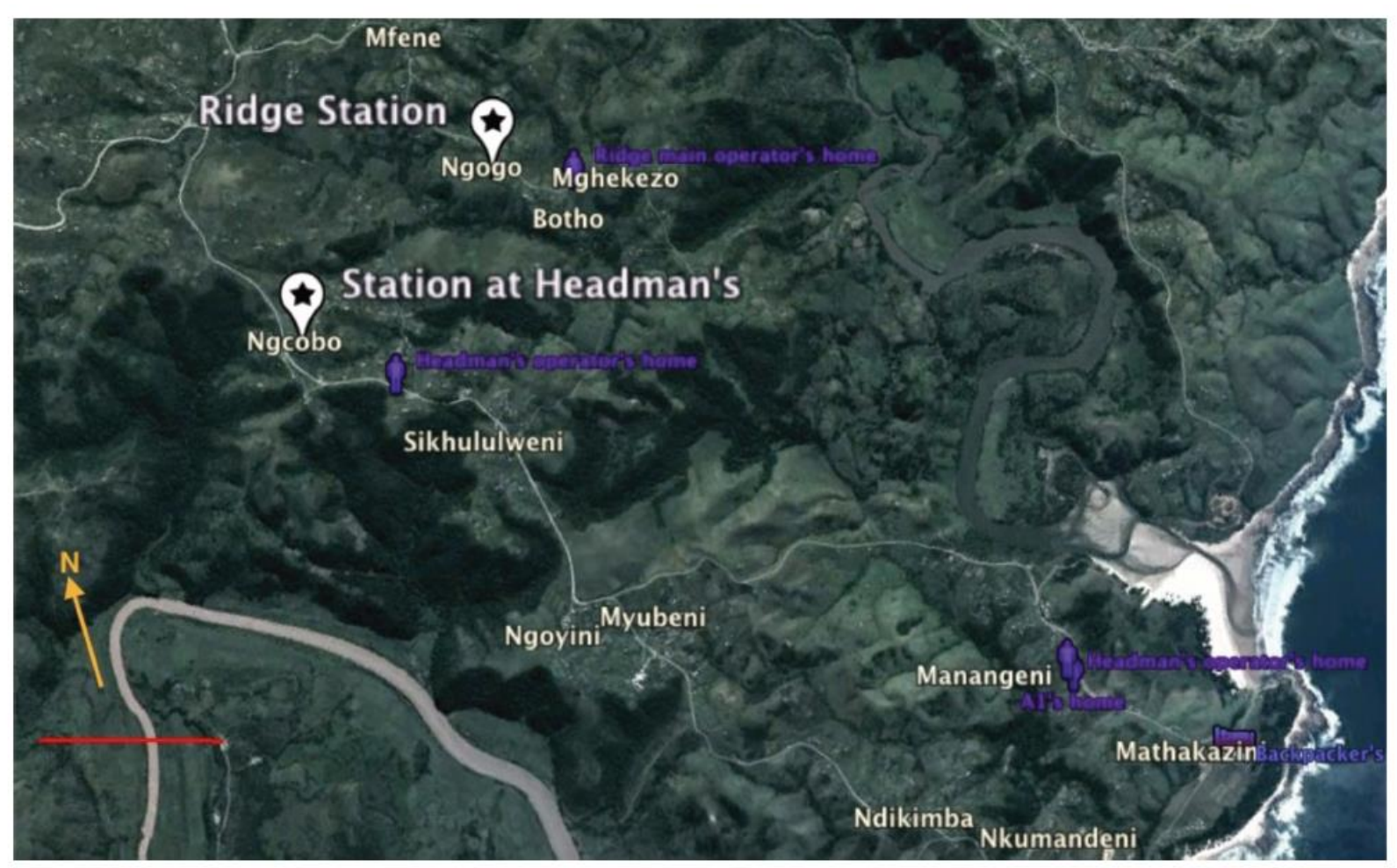

Fig. 1. Sites of Charging Stations (yellow starred markers) and homes of A1 and operators amongst Mankosi's villages. North: orange arrow; 1km: red line. (Aerial map from Google Earth.)

\section{Mankosi and prior research}

We deployed Charging Stations in Mankosi in Nyandeni municipality, along Eastern Cape's Wild Coast, where people, in clans related to the Mpondo chiefdom, live in 580 homesteads in 12 villages spread across $30 \mathrm{~km}^{2}$ (Figure 1). Homesteads are distributed across the hilly land and comprise groups of round, thatched, mud-brick, rondavals, an occasional tin-roofed dwelling, an animal "kraal" (corral) and a garden for subsistence crops. Homesteads are connected by foot-trodden paths to communal pasture, forest, water taps and dams to which most people walk, although a few occasionally ride horses or donkeys. There is only one bus, which leaves at 5am, takes up to 2 hours to traverse Mankosi and does not go to all villages. Households of up to five adults and seven children, spend from around R500 to R1500 a month on food (R1 is about $12 \phi$ in US currency), with incomes from government grants and payments from family members who temporarily migrate for work. 
Like 18 million South Africans, inhabitants are governed by a Tribal Authority, which in Mankosi consists of the Headman, 12 Subheadmen and messengers. The Headman and Subheadmen's homesteads are sites for local administration, from hosting meetings to notarizing proof of residence papers. Headmen relate by clan to chiefs and inherit their role patrilineally, but Subheadmen can be replaced and women can take on Tribal Authority roles. Colonial governors appointed Headmen 150 years ago to oversee districts; however, post-apartheid Tribal Authorities are separate from other political bodies. The Headman is paid a small government stipend but, like $99 \%$ of locals to connect to mains electricity; still he is amongst the $20 \%$ who can afford to send children to school in a city.

Our research in Mankosi was primed by experience in neighboring areas in Nyandeni, which started when we (Author-4, A4) built a solar powered Wi-Fi network between a rural clinic and hospital in order to trial health information prototypes [Tucker et al. 2007]. We located part of the Wi-Fi network at a Headman's homestead where we (Author-1, A1) lived for 3 months to undertake ethnography into local communication practices, movements and technology use, and various deliberate and impromptu situated technology activities [Bidwell 2009]. These insights informed designing a digital storytelling application [Bidwell et al. 2010; Reitmaier et al. 2012] and also provoked us to respond to the real problems that local Xhosa people have in communicating within and across villages.

\section{Ethnographic action research (ear) in mankosi}

We draw on data generated in Ethnographic Action Research (EAR) [Tacchi et al. 2003] in Mankosi for 2 years between 2010 and 2012. Our studies did not aim to address environmental sustainability directly but to improve the potential for sharing media in rural development [Watkins and Tacchi 2008]. We generated a vast range of data to understand how to enable users to record and share information within and between villages. Our approach resonates with the way "multisited" approaches [Marcus 1995] zoom ethnographic lenses in, on, and across, various physical, social, and conceptual spaces. Some of the data were structured around two software prototypes, which we deployed on an Android tablet PC, powered by Charging Stations, since few homesteads have their own solar panel or generator. The prototypes both distribute information asynchronously at the tablet or between the tablet and users' own phones across Bluetooth, and we sought to promote use by enabling users to charge their own phones when they used the tablets. In April 2011 we introduced a Media Sharer and the Stations in a SA-UK research collaboration [Bidwell et al. 2011]. The Media Sharer emphasizes sharing visual media and uses MXit, a text-based chat system popular elsewhere in South Africa, to enable users to communicate in real-time on their own phones. People used the Charging Stations but not the Media Sharer so, ten months later, we launched the Audio Repository within a SA-based design study [Reitmaier et al. 2012; Bidwell and Siya 2013]. The Audio Repository shares voices recordings, does not support synchronous communication and inhabitants continue to use it.

\subsection{Inhabitant Research and Regulation}

EAR emphasizes detecting, articulating, and solving communication problems in the community affected [Tacchi et al. 2003]. Four of us have lived in Mankosi since birth (A2,

\section{http://repository.uwc.ac.za}


A5, A6, A7), one of us (A1) for 20 months in total since 2010, and three of us (A4, A8, A9) visited Mankosi briefly. Long immersion enabled us to observe practices by participating in them, and we recorded many observations about daily life and communicative ecologies. Just as importantly, our accountability in this tight-knit community affects our lives. Those of us who were born in Mankosi were part of a team of Local Researchers (LRs), who gathered data, advised in design and translated, linguistically and culturally, between local and nonlocal meanings. Few local people speak English and we (LRs) refocused interpretations as meanings evolved during studies, dialogue and events. We formed an initial team, of five men, based on recommendations by an inhabitant who had worked on technology projects elsewhere in Nyandeni; and, later recruited three women. LRs were aged 17 to 26 years and lived locally during this research. We allocated tasks based on each LR's personal disposition, interests and confidence in translating. Like most people locally, LRs had little paid work before and some, including the youngest, head households. One received a stipend for work on child welfare projects; another earned her keep in a shebeen a stipend for work on child welfare projects; another earned her keep in a shebeen (informal bar in a homestead); two are seasonal lifeguards; and, A2 taught teenagers and, now, manages a local NGO's education centre. Most LRs speak English, are literate and completed high school. A2 has certificates in ICT literacy and two LRs have university degrees. Although LRs had more formal education than others locally, all approach traditional protocol conservatively and insisted we consult Mankosi's Tribal Authority from the start.

From November 2010 to July 2012 we met the Headman 30 times to discuss issues related to designing, trialing, maintaining and extending systems to assist communication within and between villages. We began by seeking approval to experiment with new systems that might benefit Mankosi and similar communities, and inhabitants gave the project a name: "Mankosi Communications Mobile Phone Project, Unxibelelwano." Subsequently, we met with the Headman, at his or our request, by phone, and discussed plans, problems or ideas with him and other Elders. Then the Headman held a wider discussion with the community, sometimes as part of his weekly meetings. Often 70 people (approximately $55 \%$ male, $45 \%$ female, and $60 \%$ older than 30 years) attended meetings about Stations and more came when food was available, such as when we officially launched the Charging Stations. Usually, during meetings, A1 spoke in English, others spoke in isiXhosa and LRs translated, and we recorded some meetings for later translation.

\subsection{Locally Produced Media}

LRs and other people, aged from 14 to 80 years, recorded their own audio or video, which LRs translated into English later and provided auto-ethnographic insights on values, priorities and concerns. We meant the first set of videos to introduce collaborating UK researchers to local oral practices. This set covered many topics (e.g., corruption, health, transport, local business, family history and reminiscences) and included 14 conversations or interviews between 18 different people; an opinion piece; stories by old people; a group chatting around a fire; and, presentations by tour guides in a training workshop. Six months later three young people recorded video of a match and interviews with players and supporters about how they communicate about soccer, during the launch of the local league. We uploaded

\section{http://repository.uwc.ac.za}


photos and videos of soccer matches to the tablet, along with a young man's audio commentaries of weekly matches for two months. One LR devised and recorded 10-minute interviews with five women about food and waste, and then filmed three tours around sites women mentioned in her interviews. Finally, LRs also video recorded their own isiXhosa role-plays to explain the project and oral consent to participants in studies.

\subsection{Interviews and Diary Studies}

We conducted over 90 hours of interviews individually, in focus groups and diary stud- ies with 200 people. We aimed to interview only people over 16 years but suspect some were closer to 14 years of age. We recompensed participants with airtime vouch- ers afterwards. We began six months before launching the Stations by interviewing 141 people in eleven villages about phone ownership and use [Bidwell et al. 2011a]. We interviewed between Saturday morning and Tuesday evening to include people who work outside of Mankosi on weekdays, and in homes, shebeens, along roads and paths and at football matches. These interviews showed the prevalence of using Callback ser- vices, so we interviewed another 16 people explicitly about this [Bidwell et al. 2011a]. To explore the ways people manage mixtures of communication in their daily routines we gathered data from 18 people across periods of four days or more. We began with 6 male and 6 female older, low-end phone owners (mean age: 48 years), half of whom are illiterate. Before and after diarying we interviewed participants individually or in groups, and in the intervening ten days LRs undertook 52 short interviews about in groups, and in the intervening ten days LRs undertook 52 short interviews about phone-use. LRs visited half of the participants for six or seven days and half for two to four days to review the calls, "buzzes" (deliberate missed calls) SMS, and Callbacks that participants had made or received since the LR's last visit. LRs noted details about the interactions; where participants were and what they were doing at the time; the age, gender and relationship of the person at the other end; and, whether participants had seen or expected to see that person in the previous or next day and the circumstances of this. We adapted diarying to account for younger people's interest in MXit: the phone- based chat service integrated into the Media Sharer. First we discussed using phones and MXit with a group of young people (mean age: 22 years). Then LRs interviewed four who owned low-end phones over four consecutive days, in a similar way as we had done with older people. We also interviewed six feature-phone owners over MXit for four of six evenings by texting in isiXhosa or an abbreviated English idiom.

We (UK-researcher A9, LRs) interviewed 28 feature-phone owners, mostly under 30 years of age, in groups or individual sessions inside the homes of Tribal Authority members [Frohlich et al. 2012], and inhabitant researchers (A1, LRs) also explored with six male soccer players (aged 20 to 27 years) how the tablet and phones might support the league. Further, we interviewed six women (aged 27 to 69 years) and four men (aged 22 to 38 years) living near one Station three months after deployment in depth, and another 40 people while they dropped off or collected phones at Stations. 


\subsection{Observations and Workshops}

For a year we automatically logged use of software prototypes, operators wrote daily logs about Station use and we (A1, A2) watched operation in visits to sites for meetings and checkups. We (A1) also undertook focused observation of the Charging Stations, which we recorded in handwritten notes and, sometimes, video and/or photos. In the first five weeks of deployment we observed each site for 4 hours on different days of the week and at different times of day. Three months later we observed each site for 5 hours daily for a week. We noted who brought phones for charging, how long they stayed, what they did, and the types of phones they brought. Later we walked between the Stations and homesteads of 40 people using them, logging our paths as we went. We also observed use of phones in 14 workshops of 2 hours to 5 hours, with 24 people on using the Media Sharer and with 50 people using the Audio Repository [Bidwell and Siya 2013].

\subsection{Eversion, Interpretation, and Analysis}

We formally concluded research on the Charging Stations in early 2012. We used descriptive statistics to analyse responses to any closed questions and LR logs, and thematically coded transcribed or annotated recordings and written descriptions of varying "thickness." We consider the quotations, presented here in English to suit nonlocal readers, are LRs' interpretations, because inhabitants preferred their own rich language of isiXhosa in most dialogues even if they know English.

\section{Trialling the charging stations}

We deployed two Stations that we (A3) constructed in Cape Town and (A8) reassembled in situ. Members of the Community Association, who ostensibly communicate into Mankosi's governance, suggested five sites and, after long discussions about access, security and operation, inhabitants proposed two of these, based on their knowledge of existing charging facilities. The sites were $2.5 \mathrm{~km}$ apart: in the Headman's village, Ngcobo, and 25-mins walk away, in a village in Mankosi's poorest area, identified locally as "Ridge" (Figure 1). Six weeks prior to deployment, the Headman confirmed Stations would be located in his homestead and that of a Subheadman in Ridge, which are on would be located in his homestead and that of a Subheadman in Ridge, which are on the highest hills in each village and accessible on foot. While trialling the Charging Stations we paid honorariums of about R50 per month to recompense families in the homesteads where the Stations were stored.

The Headman indicated that his secretary, at Ngcobo, and the Subheadman, in Ridge, would oversee the Stations based on their standing in the community and proximity to the sites chosen. We (A1, LRs) agreed at first, but as deployment loomed we became uneasy as both people chosen were aged over 50 years and unfamiliar with phones, and one was printilliterate. Thus, we considered alternative strategies that would reconcile with the Headman's decisions, and suggested that two LRs, living in Ngcobo and south Mankosi that could assist at Ngcobo and a young woman in Ridge, who owned a feature-phone, could assist at Ridge. Soon after deployment we realized that the complexity of the Media Sharer and demand for charging required us to do more than just assist the Headman's chosen 
operators, so we paid the LRs to work 30 hours a week per Station. We hoped that others would assume responsibility once they were familiar with the system but this caused or revealed tensions, so we remunerated others, for an hour or so a day, in the last six months of the trial, hoping to promote use of the Media Sharer, extend Station operation and prepare for its long term sustainability. At Ngcobo two unmarried male LRs (aged 19 and 24 years) who live with their families $0.5 \mathrm{~km}$ and $6 \mathrm{~km}$ away, worked for most of the day on different days and the Headman's son, 17 years old, and his wife, in her late 30s, also collected and returned phones. At Ridge a married female (aged 24) who lives $1.75 \mathrm{~km}$ from the site led operation, and the Subheadman's wife (aged early 40s) and their daughter-in-law (aged 23 years), both of whom live on site, also collected and returned phones. In the first month of deployment we ran six sessions to familiarize operators in using the Station and software, recording the battery's voltage using handheld voltmeters, and keeping daily records.

Stations operated at Ngcobo for 207 days and Ridge for 187 days during the trial from April 2011 to March 2012. Before deployment the Tribal Authority and other inhabitants proposed levying a fee of R2 per charge to encourage charging phones for only certain uses. We were worried that a fee would affect use of the Media Sharer but did not intervene as we also did not want to undercut local business. In fact the community did not impose a fee and during the trial people charged phones for free. On assuming full responsibility for the equipment afterwards, the Tribal Authority said that they would levy a R3 fee for charging each phone, to cover replacing broken components (rather than the work of operators or caretakers). In the sixteen months since the trial ended the Stations operated for roughly 80 days at Ridge and 250 days at Ngcobo. This was because inhabitants took eight months to decide where to relocate the Ridge Station after the trial and because a roof fell on the Station at Ngcobo during a recent, extreme weather event (Figure 9).

\section{Practices}

We now describe nine practices in which inhabitants participated to charge cell phones. Four of these directly relate to the Charging Stations as physical designs, not only because carrying out a practice often means using certain objects in a certain way, but also because our designs shaped practices while practices influenced the modifications we made.

\subsection{Setting Up and Moving the Station}

The operators arrived between 8:00am and 9:0oam on weekdays, on most Saturdays at Ridge, and on 13 Saturdays at Ngcobo. They began by setting up each Station, which included solar systems mounted on hand carts (sack trolleys), with small panels and one battery at Ridge (Figure 3) and larger panels and two deep-cycle batteries at and one battery at Ridge (Figure 3) and larger panels and two deep-cycle batteries at Ngcobo (Figure 2(b)). Our design aimed to ensure people could protect Stations from criminal intent and the elements. 

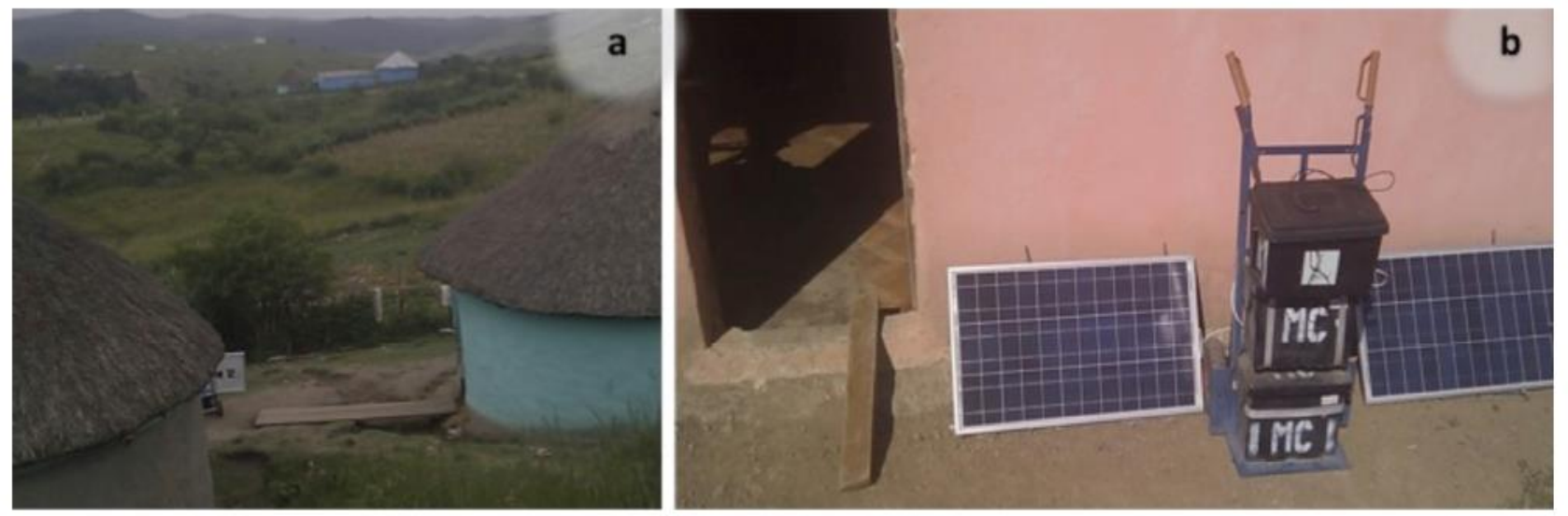

Fig. 2. Wooden bridge at Ridge (a); Plank over the doorframe at Ngcobo to guide Station (V2) (b).

It was partly inspired by A1's prior improvisation of carrying a solar panel indoors each day, after a man had tried to remove a panel from her bedroom roof one night. Operators pushed the carts from their storage places-in the corner of the office in a two-room building in the Headman's homestead (Figure 5), and in the Subheadman's sleeping rondaval in Ridge (Figure 2(a)). They stored and moved the Stations with the solar panels adjusted in parallel to the handles of the carts so they were narrow enough to fit through the 'person size' doorways of rondavals. A family member in the homestead, or someone else, often helped operators manoeuvre the carts through the door of the Headman's office and across a deep trench surrounding the Subheadman's rondaval in Ridge. After a month, operators at Ngcobo started to use a short plank, found behind the office, as a ramp over which to ease the bulky cart over the entry (Figure 2(a)).

At Ridge we constructed a wooden bridge between the door and a flat area $3 \mathrm{~m}$ away (Figure 2(b)). In contrast to how they moved the tablet around and between homesteads, the operators rarely moved the cart more than $4 \mathrm{~m}$ from the door in Ridge or $1 \mathrm{~m}$ from the door in Ngcobo, which has flatter ground. Occasionally, when there were many people at the Ridge site, the operator moved the cart 10m away from the door (Figure 4(a)) and, since the trial, the Headman moved the cart 12m away, in front of another building where he stored it until the roof of that building collapsed (Figure 9). Generally, though, inhabitants interpreted the Stations' affordance for mobility in a limited way even though the cart rolled well on A3's suburban lawn and despite the pneumatic tires that cushion components (Figure 4(a)). In fact a serious puncture to a cart tyre at Ridge made no difference to where the operator set up the Station.

With the cart in position, operators set up the solar panels, often while interacting with people bringing phones to charge. For the first eight months they assembled the panels by removing the bolts holding the panels parallel to the cart's handles and then used these same bolts to affix the panels perpendicular to the handles, since A3's design used fastenings that were all the same thread and diameter. Operators put bolts on the ground during setup and never lost a bolt, but moving the panels into place took practice and a part of a multi-

\section{http://repository.uwc.ac.za}


charger was cut within two weeks of deploying a Station, after it became trapped between a panel and the handle during set-up (Figure 4(b)).

The set-up changed over the year because of weather conditions. In Ngcobo operators laid both panels against a wall to increase solar efficiency in the summer and when high winds destabilized the cart (Figure 2). In Ridge the operator laid a panel on the ground because the wind weakened its mounting (Figure 4). Sometimes operators rotated the carts, about their wheels, to maximize sun exposure if they noticed the angle of the sun, but they were not consistent about this and in Ridge the panel was often shaded in the afternoon.
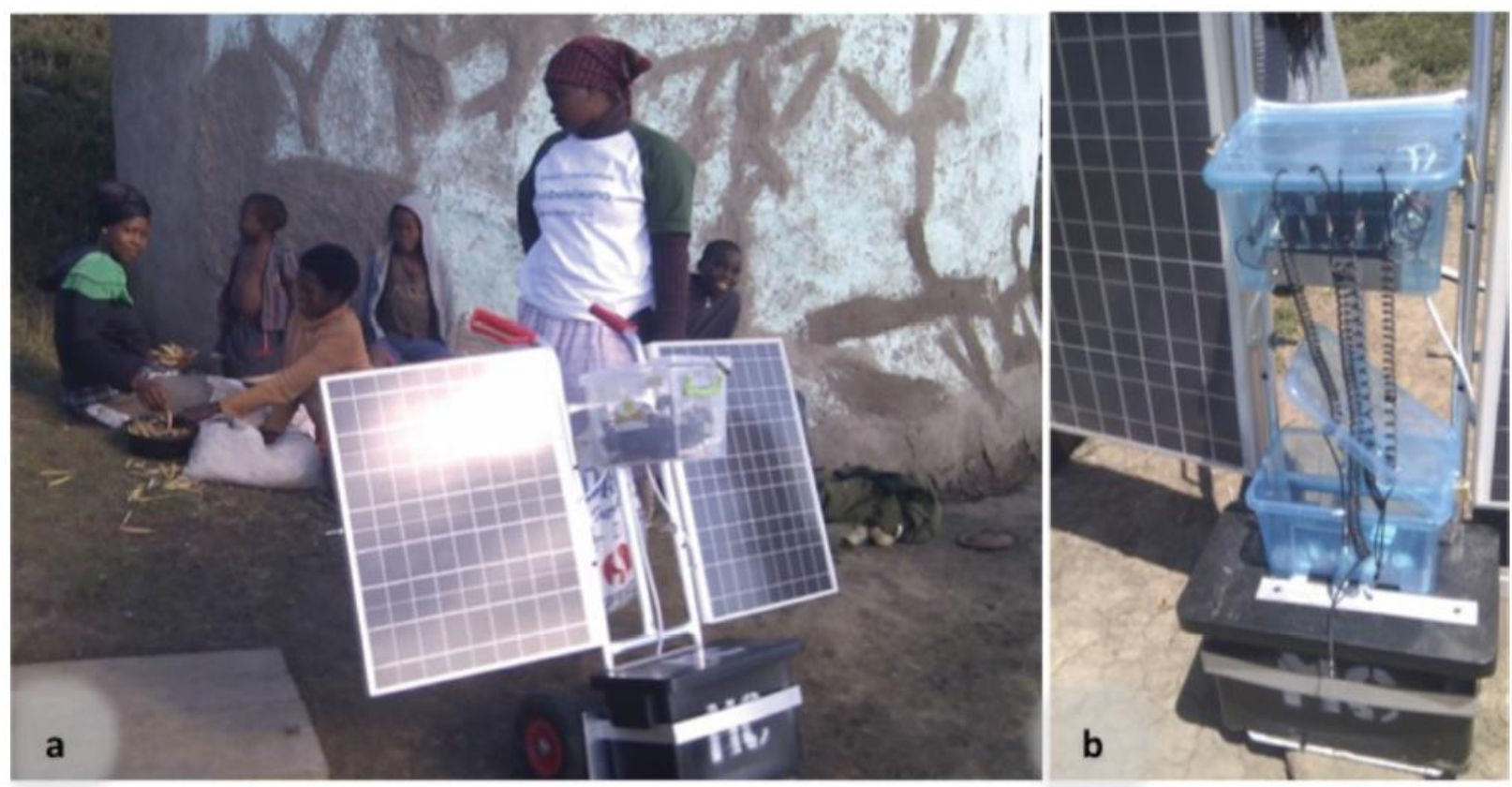

Fig. 3. Smaller Station in Ridge showing component storage box in Version 1 (a) and lock-hinge and connectors fed into lids in Version 2 (b).

Routines on rainy days for Stations differed. If it was raining when operators awoke they did not go to work, so both Stations did not operate for a total of 50 days across the trial. For 11 days at Ngcobo and 16 days at Ridge, logbooks recorded that rain started after operators arrived, so they brought Stations inside and took them outside again if the break in the rain seemed long enough to warrant it. Operators reversed the set-up process to move the Stations back into the rondaval at Ridge, between 2.30pm and 4:00pm, and the office at Ngcobo, between 1.30pm and 2.0opm. For the latter, they left the plank for the ramp outside.

\subsection{Recording Voltage and Connecting Phones}

Once they had set-up the Charging Stations, operators recorded the battery's voltage using a multi-meter and started connecting phones for charging. We (A1) marked red lines at oV and $12 \mathrm{~V}$ on the multi-meter and taught operators to make positive and negative contact with insulated components without any phones connected. Early in the trial one operator made contacts in potentially unsafe ways and was also concerned that charging the battery over $12 \mathrm{~V}$ was dangerous. Average voltage readings at the end of operating on sunny days were $12.63 \mathrm{~V}$ (st

\section{http://repository.uwc.ac.za}


dev. 0.31) at Ngcobo and $12.45 \mathrm{~V}$ (st dev. 0.23) at Ridge. Average readings for the 53 and 47 rainy or cloudy days were, respectively, $12.3 \mathrm{~V}$ and $12.21 \mathrm{~V}$ at Ngcobo and $12.4 \mathrm{~V}$ and $12.17 \mathrm{~V}$ at Ridge. If the voltage read under $12 \mathrm{~V}$ operators waited until it read $12 \mathrm{~V}$ before connecting phones in order to prolong the battery's life.

Operators interacted with people while connecting phones, which affected their attention to components. Our original design placed charging components in a storage box and left cables and connectors exposed (Figure 3) but the storage box became cluttered and operators often moved phones and components inside the box and hung phones by charger cables when swapping chargers to suit phone models. This weakened and entangled the charger cables, so we (A1, LRs) mounted the regulator and lighter socket on the walls of the boxes (version 1.2). Although this reduced clutter, operators continued to hang phones by cables, so after 6 months we replaced the box on operators continued to hang phones by cables, so after 6 months we replaced the box on the cart at Ngcobo Station with a larger one to afford room to lay phones (version 2.0).

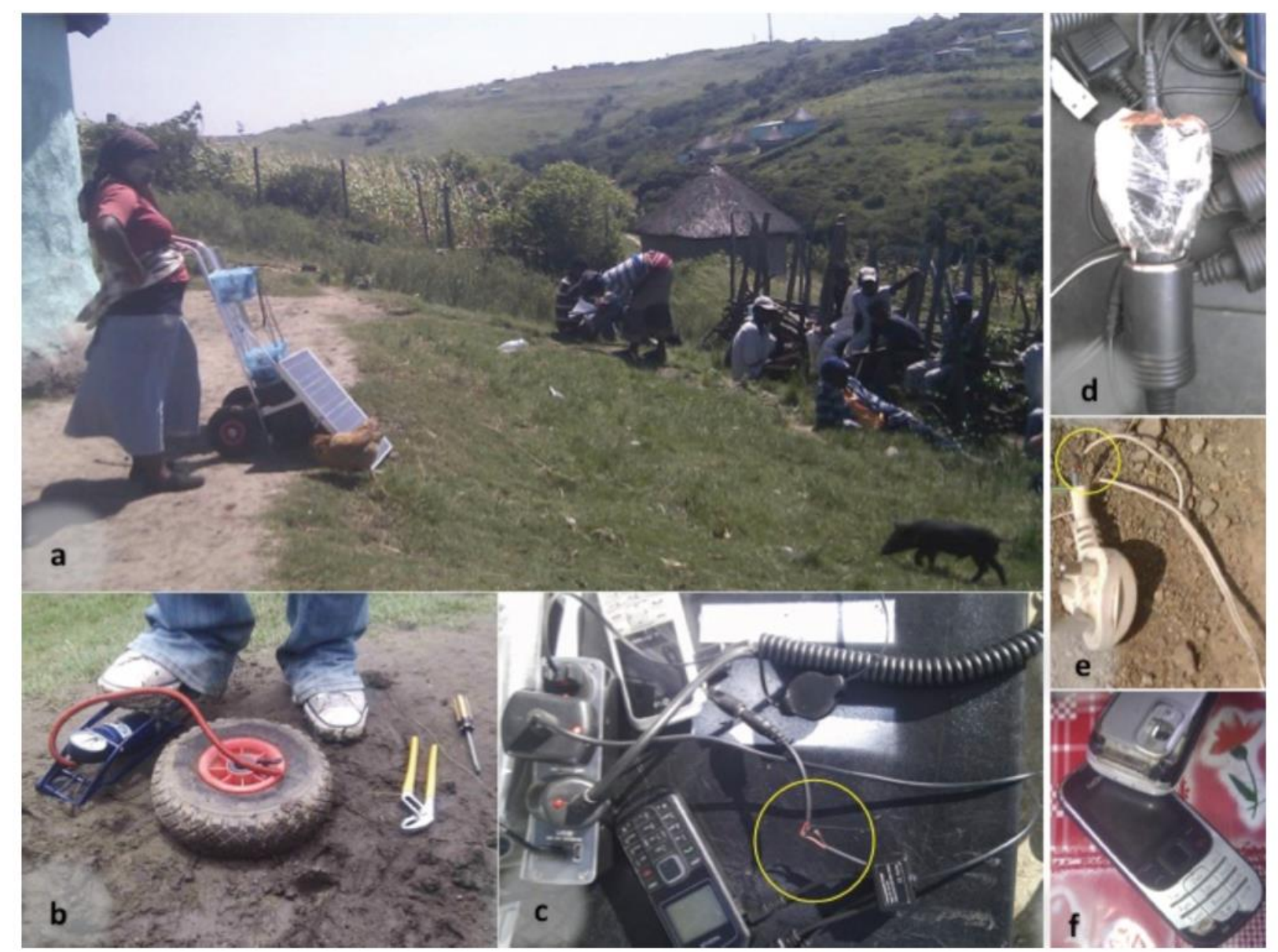

Fig. 4. Final version of Ridge Station moved further from the rondaval than normal because of a meeting a weakened panel is not attached to the cart (a); broken components at Ridge (b); repairing a tyre during a break in the rain in the wet season (c). Examples at Ngcobo of: operator-repaired charger (d); plug to Headman's generator (e); and, inhabitants' phones (f). 
To begin with we did not account for sufficient headroom when chargers were inserted into the socket so operators left the lid off and wiggled chargers to make electrical contact between dusty connectors. We re-positioned the lighter socket and chargers to enable replacing the lid which, if operators remembered to do so, reduced dust. There are no surfaces to store phones at Ridge, other than two beds in the Subheadman's rondaval; thus, we separated the socket and chargers from phones to reduce weight on the cables and prevent tugging (version 2.0). We arranged two storage boxes vertically and drilled holes in the lids of boxes through which we fed charger cables (Figure 3).

Our design did not include an inverter to provide mains power and logs and observations, during the trial, suggested that inhabitants used the Stations exclusively to charge phones and the tablet. Indeed, inhabitants own few other electrical devices other than batterypowered radios [Bidwell et al. 2011a]s. The Headman was eager to ensure only operators handled the components, but on a few occasions fuses had blown, wires pulled from units, and video uploaded to the tablet when operators were not there, which led us to speculate about his family's use outside of hours. After the trial ended the Headman said that when his son had overseen the Station a charger broke.

\subsection{Fixing Stations}

If the voltmeter displayed oV operators phoned us (A2). This usually meant a fuse between the battery and the regulator had blown and normally, except for one month at Ridge Station, we (A1 or A2) went to the Charging Stations within a week to replace fuses. A3's design meant that we were able to access components and once we were familiar with problems we (A2) fixed them, using small repair and tool-kits. However, it also meant operators, or others, used faulty chargers or customized the Stations in ways that compromised longevity and safety. Rather than customized charging hardware, A3's design used a standard 12v moulded plastic cigarette lighter socket that accepts a USB cable and three car chargers. During the trial we replaced one fuse, two chargers, and a socket in Ngcobo and ten fuses, three chargers, and a socket in Ridge. At Ngcobo a charger broke, and someone attempted to re-assemble it, which blew the inaccessible fuse in the cigarette lighter socket. Someone also spliced other chargers onto the wires from the car socket, which means that if all chargers are connected they draw excessive current, undermining the battery's longevity. The small pins of Nokia chargers were especially fragile and malleable and unsuited to the constant use that resulted because $80 \%$ of phones locally had this design [Bidwell et al. 2011a].

People who are not exposed to electricity regularly, and do not have suitable materials (e.g., insulating tape), can create circuits that are unsafe and/or draw current exceeding fuse resistance. For instance, lying in a trench outside the Headman's office are exposed wires that he uses to connect his TV to a generator run once a week (Figure 4(e)). Similarly, within ten days of the end of the trial the Subheadman's daughter-in-law at Ridge accidentally detached wires from the regulator and the fuse holder and, as we could not source the same fuse holder locally, we replaced it with one with the same power specifications. Chargers and the socket also broke at Ngcobo and the Headman waited ten days until we (A2) could visit to fix it and, during that time, he could charge only one phone at a time. 


\subsection{Charging Phones}

Operators aimed to return phones fully charged and each phone took 2 to 5 hours to charge, depending on the age of the phone's battery and the charge in the Station battery. They charged from 2 to 17 phones a day in Ridge, and from 2 to 24 phones a day in Ngcobo (Figure $7(\mathrm{a})$ ), on a first-come-first-served basis; but, their practices while phones charged differed between the two sites. Operators in Ridge worked outside, and the main operator went home during most days, but in Ngcobo operators distributed work between the Station outside and the office inside, and remained at the site across the day.

At Ridge, the Subheadman's wife or daughter-in-law handed the operator between three and six phones that had been left since the main operator departed the previous day. After connecting phones to charge, she entered details in the logbook, locked the storage boxes and, at some time between 10:00am and 11:00am, walked home, with the bag containing the tablet, logbook, and voltmeter in it, to undertake domestic tasks. She became familiar with how long it took to charge individual phones and usually returned to replace fully charged with uncharged phones at midday, but returned earlier if there were many phones to charge. While the operator waited for phones to charge, or was visited by other researchers, she sat on the ground next to the Station and chatted to other women, such as the Subheadman's daughter-in-law while she did chores (e.g., cooking, washing, feeding children, weaving hair) (Figure 3(a)). Between 2:30pm and 4:0opm, she disconnected phones, locked the storage boxes, dissembled and moved the Station and carried her bag home.

In Ngcobo operators remained at the Station until 2:0opm, checking on phones charging about every half an hour or so and, meanwhile, organizing phones and receiving and returning phones to people arriving at the office. Operators used a table to store phones and record entries in logbooks and sat on chairs (Figure 3), where they store phones and record entries in logbooks and sat on chairs (Figure 3), where they also used the tablet and chat portals on their phones. Provided the Station's battery reading was high, they also left over two or three phones charging in the office at the end of the day. 


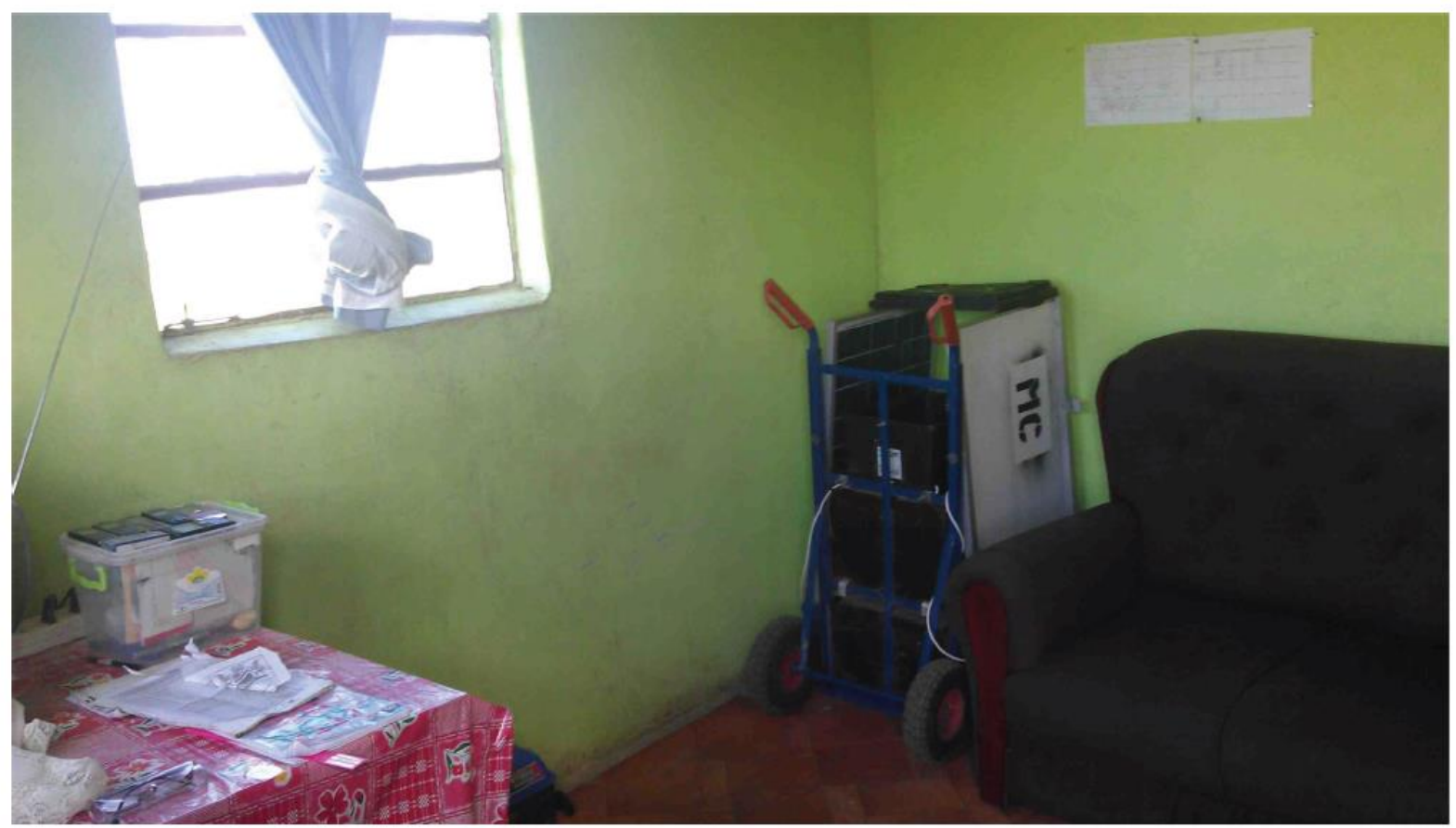

Fig. 5. Final version of the larger station stored in the Headman's office in Ngcobo. The operators left phones for collection on top of an old storage box on the table.

\subsection{Storing Phones}

The Ngcobo operators and Headman's family members left phones on the table in the Headman's office. People treat the Headman's homestead with some formality, as it is the central site for Mankosi's administration, and will not enter the office, although the Headman usually sits some 3om away from it. Also the Headman's homestead is enclosed by a tall wire fence and his bedroom adjoins his office. The Ridge site does not carry the same authority as the Headman's homestead, is only partially enclosed by a low hedge and is visible from nearly $180^{\circ}$ at $0.5 \mathrm{~km}$ away. Further, the main operator did not live in the homestead, and the area has a reputation for more "tsotsis" (petty but sometimes armed criminals). Thus, in response to concerns about theft of phones, we drilled into the storage box and inserted two padlocks: one to act as a hinge and the other as a lock (Figure 3). The main operator locked the storage box whenever she left the site. For the first few months she locked charged, uncharged and charging phones in the box, and as the Subheadman's daughter did not have the key to the padlock, anyone who came to pick up a phone when the operator was not there had to return later or another day. After a few months the main operator stored only uncharged and charging phones in the box and before she left the site handed charged phones to the Subheadman's daughter to return them to their owners.

\subsection{Receiving, Returning and Organizing Phones}

Operators interleaved receiving, organizing phones, setting up the Stations, connecting phones and talking to people who arrived to deliver or collect phones. In Ngcobo, operators arranged phones that awaited charging in the order they were delivered, either in two rows, or with charged phones laid on top of an old storage box (Figure 5). For the first six months operators

\section{http://repository.uwc.ac.za}


wrote phone owners' names on labels or small strips of paper which they attached to charged phones (Figure 5), but did this less frequently when they became familiar with who brought phones. Operators asked the Headman's wife or son, when they saw them moving around the homestead, about any phones delivered prior to their arrival that they did not recognize. To address concerns about theft of phones, phone batteries, and airtime, they always ensured all phones were turned off and, to begin with, wrapped colored bands, that we provided, around damaged phones (e.g., Figure 4(f)) to prevent the batteries from falling out. At around 1:45pm operators checked the rows of phones that they left for the Headman's family to return to owners later or store, with the tablet, overnight in the office.

In Ridge the operator said that she charged phones in the order they were delivered, including any delivered prior to her arrival or while she set up, but did not a have a visibly discernable arrangement (there are no flat surfaces at the site). Again to avoid accusations of airtime theft, and even if phones had PIN codes, she ensured all phones were turned off. The Ridge operator waited between 2:30pm and $4 \mathrm{pm}$ for people to pick up phones, and then left the Subheadman's daughter any that were not collected.

\subsection{Writing in the Logbook}

Operators recorded the times they set up and put away the Stations, their batteries' voltage, weather conditions, the names of people bringing phones for charging and/or using the tablet, and the times people delivered and collected phones. Across the trial we provided 10 and 11 exercise books to Ridge and Ngcobo operators, respectively. For the first two months we (A1) marked columns across two facing pages for each day and then operators copied this. All operators always wrote the name of the person delivering or owning a phone and ticked these off or wrote the time of return. However, while one operator always wrote the drop-off and pick-up times, and voltage at the start and end of the day, others were less consistent. In Ridge the operator often wrote down the same time each day for phone collection, set-up and storage but this did not always align with observations. More interestingly, operators at Ngcobo often entered the same person with different identifiers and related people to each other. First, operators might know a person by alternative names so, for instance, the same woman was written "Wendy" and "No-Amen" on different occasions and, also, used various respectful prefixes, including "Mr.," "Tata," "Ma," and "Mama." Second, operators indicated if a child brought the phone of someone in their homesteads by noting their relation to the phone owner, for instance, to write Wendy/No-Amen (the woman above) as: "Ma ka Khuselwa or "Ma ka Mopitilizi" and "Ma ka tamara."

\subsection{Bringing Phones}

An average of 11 (stdev 3.5) and 8 (stdev 3.5) people arrived each day to charge phones at Ngcobo and Ridge, respectively. Over the trial 325 and 340 different people brought or sent someone to take phones to charge at Ngcobo and Ridge, respectively (after adjusting for spelling, name variations and family relationships). In Ngcobo this included $51 \%$ females and $49 \%$ males, and at Ridge $58 \%$ females and $42 \%$ males. 
From the start the Tribal Authority and other inhabitants asked that we (A1) dictate rules for use, suggested some rules and encouraged us to place notices at each Station. We (A1, LRs) made signs explaining, in isiXhosa and English, drop-off and collection times, that only one phone per person could be charged and that people should not bring others' phones. However, people often ignored the signs we installed, removed the first signs at Ngcobo and brought more than one phone despite the signs (Figure 6(a), 6(b), 6(c)). Inhabitants do not wear watches, so if their phones are uncharged or charging they lack personal access to the times of operation defined by the rules. At Ngcobo, on average $50 \%$ of phones were dropped off within two hours of the times indicated on the signs. Women were slightly more likely to arrive a little earlier than men, and were signs. Women were slightly more likely to arrive a little earlier than men, and were less likely to arrive much later than the signs requested. People usually did not carry anything to Stations, other than phones. If they did carry something else it would be a traditional stick, for men, or an empty bucket or small bag for women, and never anything heavy (such as fuelwood), which suggests they did not walk up the hills to charge phones on their way from a domestic task.

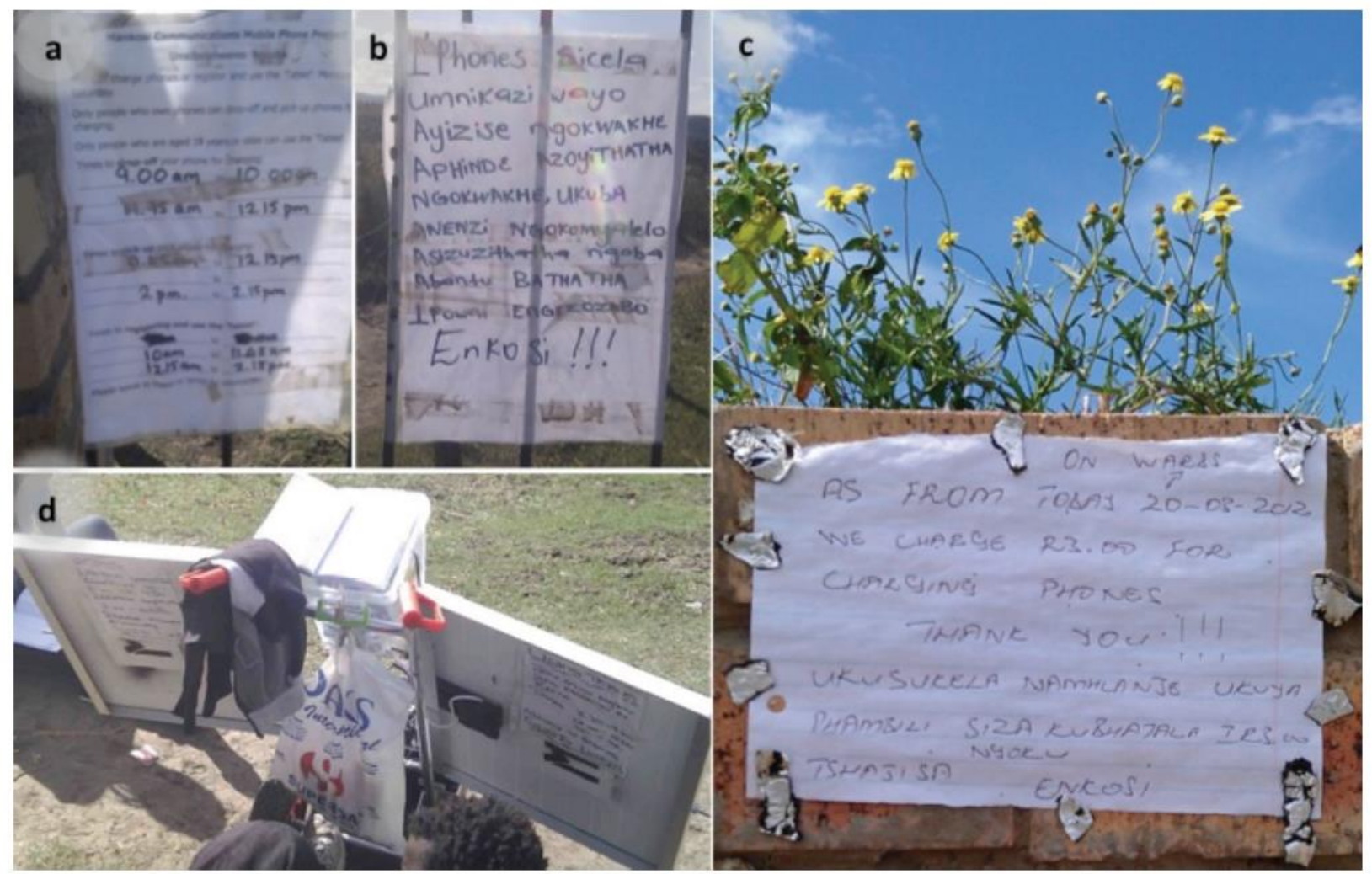

Fig. 6. Signs about rules for charging, urged by inhabitants and decided by LRs during the trial (a, b, d). Signs at Ngcobo placed on the homestead's gate were removed (a, b) - translation (b): "We ask that only the owners of phones to bring them and collect them, if you are not doing that we will not charge phones. Thank you". After the trial the Tribal Authority erected a new sign at Ngcobo about a tariff for charging (c). Signs at Ridge remained on the cart throughout the trial (d).

People tended to drop phones off later in the first and last few months of the trial, because of weather, seasonal work and the Headman's family's formalized involvement. Ngcobo operators said that telling older people to keep to certain times was impolite. Practices in

\section{http://repository.uwc.ac.za}


Ridge made it easier to enforce drop-off rules, as the operator was not at the Station throughout the day, but this also led to complaints.

Most people came more than once, but fewer than five times, to one or both Stations (Figure 7(b)). Men charged more often than women in general, but women who regularly charged at Ridge did so more often than men. Many more people charged phones around Christmas, but in a normal week people charged more on Mondays as they made most calls on weekends when call rates are lower (Figure 7(a)). At Ngcobo, relatively more women charged on Monday and fewer on Thursday or Friday when many go to church and prepare for the weekend. People brought phones to charge when they attended the Headman's weekly meeting at Ngcobo, so $19 \%$ of those who charged on Tuesdays did not live in Ngcobo, compared with $13 \%$ on Mondays.

People walked between $0.25 \mathrm{~km}$ and $4.0 \mathrm{~km}$ to drop off or pick up phones. At Ngcobo the most frequent users, other than the operators, were people who lived in 21 homesteads within $1.5 \mathrm{~km}$ and Tribal Authority members who had walked several kilometers from their homesteads. The 21 homesteads were on average 1100 (stdev 500) steps away along a direct route to the Station and fairly equally distributed in all directions around the site. Men come to the Headman's homestead from across Mankosi so they tend to have walked further.

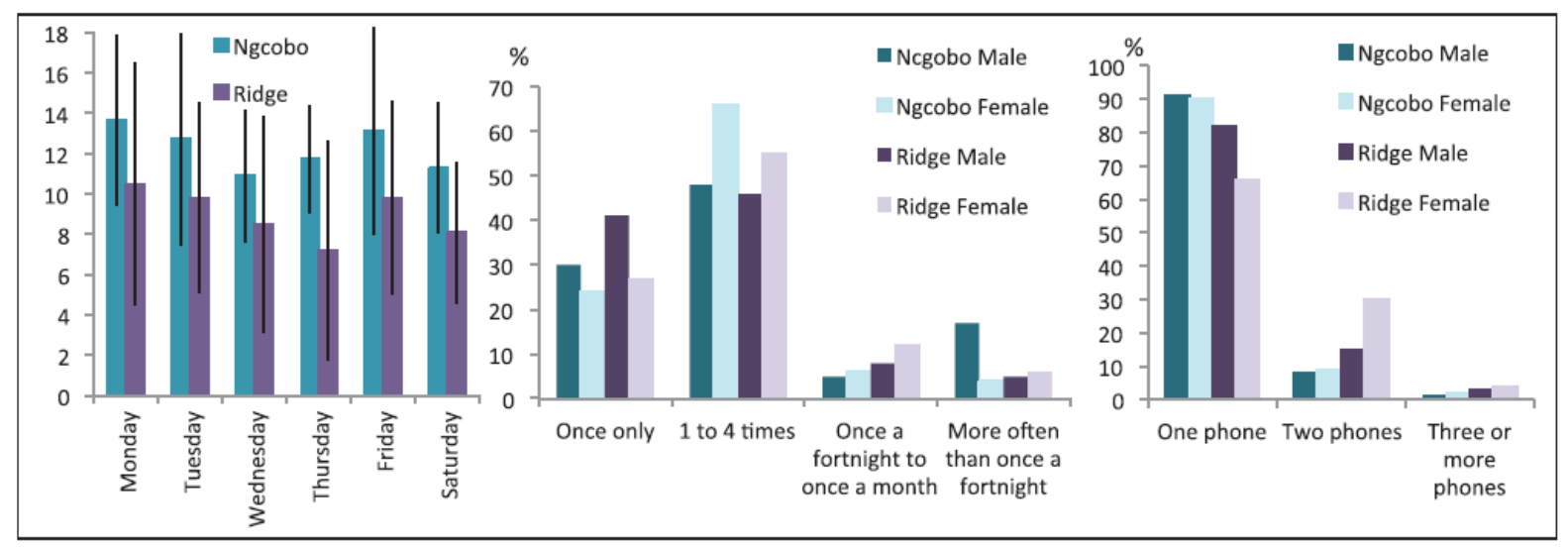

Fig. 7. Mean number of phones charged each day of the week across the year at the Stations (a); Percentage of males and females charging once only or more regularly (b); Percentage of people who brought one or more than one phone to charge (c).

For instance, some $20 \%$ of males and $12 \%$ of females walked more than $2 \mathrm{~km}$ to Ngcobo Station, whereas $6 \%$ of men but only $2 \%$ of women walked $5 \mathrm{~km}$. People who charged phones at Ridge Station live in homesteads that are either close to the site to the west of the Station or over a more extended area to the east. Homesteads to the east did not have as good a line of sight with the Station as those to the west, and the people that primarily charged phones lived in homesteads that lay off the track in the same easterly direction as the homestead of the Station's main operator.

About $65 \%$ of Mankosi inhabitants aged over 14 years own a cellphone [Bidwell et al. 2011a], but not everyone who brought a phone to the Stations was able to charge. Once they realized 
this they continued to charge at one of three homesteads in both Ridge and Ngcobo that they had used before the Stations' deployment, and paid R5 to do so. Sometimes this reflected the availability of appropriate charger models; for instance, we could not buy car-chargers for some Samsung models, nor supply sufficient chargers for Nokia models, which were most often used and are very fragile. About $30 \%$ of men and $20 \%$ of women said there were insufficient or no chargers for their phone models. Occasionally people brought a charger with them, but most cannot source or afford these. Some men said they charged somewhere that was more convenient, such as near a workplace at the other end of Mankosi.

From early in the trial men living in homesteads to the west of Ridge station told us (A1, A2) that they were not receiving service and later $65 \%$ of 20 men who lived in Ridge said they been unable to charge at the Station. Half of these men said the operators prevented them, and that the operator and/or Subheadman's family "bring their friends' phones". Yet, $80 \%$ of 18 women discussing the situation said they were always able to charge even though this meant that they left phones for more than a day and charged once a week or less. Although men accused operators of favoritism it seems that it was operators' visibility that enabled some people, but not others, to integrate using the Stations into their routines. Ridge's main operator did not remain at the Station all day, and people saw her walk up a path and along a track from home, then across a grassy ridge and up the hill to the Station. Some women said they predicted her coming and going in the context of their own routines; for instance, they saw her walk up the hill while cooking, so paused cooking or sent a child to collect phones. The same did not apply as much to Ngcobo because both operators remained at the site all day, although the operator living in Ngcobo brought his neighbors' phones, and the operator living further away often passed twenty people as he walked to work (on the roa of the hill where the Station was sited).

\subsection{Collecting Phones}

The person who collected a phone often differed from the person who brought it, despite rules and signs (Figure 6(a), 6(b)). Many inhabitants sent children and at Ridge this was sometimes prompted when they saw an operator walk to the Station. Some always sent the same child; others the child that was closest; and, sometimes children walked together. Whichever way though, operators recognized children, knew their relationships with phone owners and rarely worried that phones would not be returned to their owners. This caused sporadic problems. At Ngcobo operators were accused of stealing airtime when they returned a phone to its owner via another person. At Ridge, a man came to pick up his phone that a child had delivered, but the phone was blocked, signifying repeated entry of an incorrect PIN code; and, a Tribal Authority member had a memory card stolen from his phone. Around $60 \%$ of inhabitants arrived at Ngcobo Station to collect phones before operators left for the day but often people did not collect phones for two days at Ridge. Some mentioned that they missed calls during this time, but rarely complained and, indeed, expectations about phone use altered only subtly; for instance, most people said that they did not use their phones for music any more than when they had to pay to charge their phones. 


\section{Walking along in sustaining practices}

In our preceding representation of practices we often delineated routines at different loci of interactions with objects or at locations, such as Station components, logbooks, phones and outside or inside the office. Yet, inhabitants interleaved routines, related to the Station, and this extended over much wider spatial and temporal scales. Objects and locations enabled us to organize our account around origins, intersections, and termini but these points did not neatly punctuate the mundane practices of operators or users of the Stations. These points are linguistic, mathematical and tangible tools that help us to perceive orderliness while we inhabit the world topokinetically.

Hui [2012] argues for incorporating the mobility of objects and people into observations and accounts, and shows that equipment acquires different qualities when stationary and when in different forms of travel. She suggests that objects are mutable and their appropriation "is inseparable from the work of moving materials around". Thus, mobility establishes links between objects and routines that are stable during that specific travel and "mobile practice networks are enacted as temporary accomplishments". A Charging Station, then, has a set of links while stored, another set while moved from storage and more sets while in operation and put away. At the same time a phone has its own sets of links: when it lies in a home uncharged, while its owner or someone else takes it to charge; while carried; while organized by the operator; while being charged; while being stored; when collected, and so on. We focused on a limited subset of movements in managing and using Stations and, thus, only articulate some links, and some qualities of Station equipment and phones. Our classification obscures connections between elements, which must be integral to practices if, as Reckwitz [2002] asserts, practices depend on this specific interconnectedness and cannot be reduced to any single element. Our account cross-referenced practices in operating Stations; but we rarely mentioned the many walks that interconnect routines, people and objects and that, meanwhile, embody knowledge, know-how and sociality. We abstracted aspects of routines to separate them from the movements that interpenetrate them. However, although such abstractions can help theorize, Cresswell (2010) reminds us that the experienced and embodied practice of movement is always entangled with both physically translating from one place to another and representing that movement to share meaning about it. He argues that at any one time certain constellations of patterns of movement, representations and practices exist but these elements only make sense together [Cresswell 2010].

As inhabitants (A1, LRs) we were acutely aware of relationships between movement and electricity because it affected daily life and research coordination. We always walked at least $0.75 \mathrm{~km}$ to use mains electricity to charge phones and we were familiar with each other's access to electricity because planning activities often took many attempts over a few days when the phones of people involved were off or uncharged. In contrast, those of us who stayed for short visits (A8, A9), did not have to co-ordinate inhabitants' participation in interviews, workshops or in deployment and meetings; and, spent hours using electricity, at the local backpackers where we stayed, to code, process, translate, and back-up so that the technologies we left and the data we took home were as complete as possible. 
The meanings we make about other's practices inherently reflect how our own bodies, as Ingold [2011, p. 95] writes, "have become accustomed, by the lives we lead, to certain kinds of movement." External researchers (A8, A9) drove hired cars throughout visits but inhabitant researchers drove A1's 4WD car only for distances of over $3 \mathrm{~km}$, due to the steep, potholed gravel road and, often, muddy tracks, and the inaccessibility of petrol and replacement parts. A2 also drove A1's quad-bike, when A1 became too nervous to drive herself, and sometimes carried others of us, to the amusement of those we passed. If we drove we gave lifts to people we passed on the road and research participants but operators usually walked to Stations. One LR used the project's bike to cycle to Ridge, but other LRs were uneasy in using it.

Buscher and Urry [2009] call for research methods that are "on the move" to better articulate relations in mobilities and Law [2004] argues for alternative method assemblages in theorizing about the relationalities in others' realities. Researchers and designers assign qualities of practices, in settings that are unfamiliar to them, to categories that belong "to someone peering 'out there' into 'their' world" and not to categories produced by inhabitants of that world [Taylor 2011]. Law [2004, p. 5] explains how research methods embed a mostly hidden assumption that "the world is properly to be understood as a set of fairly specific, determinate, and more or less identifiable processes" and that this assumption directs our attention to "what is most important in the world, the kinds of facts we need to gather, and the appropriate techniques for gathering and theorizing data." Our preceding account of practices, in managing and using Stations, laterally integrates observations around locations and vertically integrates observations about routines into delineated practices. Yet, as inhabitants (A1, LRs), we produced meanings about the Stations continuously in many interactions far beyond merely observing sites. This sensitizes us to the way an upwardly integrated account omits the infrastructures in which practices around the Stations gained meaning and the knowledge and know-how that constituted local perspectives on the Stations' sustainability.

\subsection{Local Legibilities}

Ingold [2007, 2011] reminds us of postmodernism's taste for the fragmented line, and suggests that we know as we "wayfare" along in life, in a movement that is continuous, openended and has neither a point of origin nor any final destination. We had many meetings to plan for trials and post-trial operation but, although inhabitants answered questions regarding future use, their discussion focused on current operation and, even 5 months into the trial, the Headman said it was hard to think about long-term maintenance.

Actually, different perspectives on use and operation emerged along the trial, especially with respect to Ridge. Just before the end of the trial the Tribal Authority said Ridge Station was "not helping the community," though women in Ridge thought differently. The Tribal Authority said that practices at Ridge were "a way of complaining" ferently. The Tribal Authority said that practices at Ridge were "a way of complaining" by the Subheadman's household. Indeed, three months into the trial the Subheadman had requested a higher 
honorarium because his family returned phones to owners and his wife had said that people arriving outside of operating hours disturbed her and the Station damaged the floor of the rondaval and threatened her security. At that stage we suggested relocating the Station, but the Subheadman preferred it remain in his homestead and his wife said, discontentedly, that she could not override his decision. The men paid no attention to the Subheadman's wife's concerns about crime, and advised us (A1) not to give her a phone to improve her safety. Thus, we agreed to remunerate those who returned phones if they learned to manage the Stations, hoping this might help the Subheadman's wife and improve operation during the impending wet season. However, in different meetings prior to the end of the trial, the Tribal Authority said that there was "carelessness in the house," the Subheadman was concerned that his family would be accused if the Station broke and his wife worried about regulating use and managing dissent. Other women in Ridge expressed different views. They insisted that there would be no disputes and questioned why, at the end of the trial, the men had both dictated the fee for charging and claimed security was a problem in Ridge, when no phones had been stolen in the past year. The Tribal Authority said privately that they intended the Station to remain in the homestead to avoid allegations of favoritism but when we (A2) went to Ridge to collect the Station to repair it, after the trial ended, male members of the homestead referred to gossip that the Tribal Authority sought to relocate it. They reiterated Ridge residents' views that the Station specifically serviced their area, even if it was owned by Mankosi as a community, and stopped us from moving it without another discussion with the Headman. These different perspectives on sustaining Ridge Station were not generated by dissecting and reifying aspects of routines using a uniform, orderly schema, such as those applied in creating rules about charging or to organize our preceding account of practices. Rather, they emerged in relations that constitute the routines of charging and other aspects of life.

Practices are understandable to the agent(s) who carry them out [Reckwitz 2002], but translating ways of knowing, wanting, desiring and feeling between cultures and languages and across time and places is inexorably tenuous. Dourish and Bell [2011] apply the term "local legibility" to the meanings that emerge in interactions in everyday settings, objects and actions. They refer to Scott's [1998] description of African polycrop farming, which ensures sufficient yield by drawing on a farmer's long-term, repetitive encounters with their environment and narratives about it. Thus, to interpret the various infrastructures in which practices around the Stations gained meaning, we now consider other practices in which inhabitants consume resources. We focus on relations that arise in walking as our (A1, LRs) own electricity use involved walking but our upwardly integrated account of Charging Stations, here, obscures it.

We start by depicting routines, as the number of steps people take daily, to show that walking varies and differs from averages in the West (e.g., the average 6,000 steps walked daily by Americans adults, unless they live without technology, when they can take over 18,000 steps; Bohannon [2007]). This leads to discussing relationships between walking, resource use and sociability, such as practices of communality and belonging. Then we describe ways that enduring connections between people are embodied in the corporeal walking body and in 
the spatio-temporal trace that is forged by walking and, finally, suggest that meanings about social relations may be more potent than those about conserving the natural environment.

\subsubsection{Inhabiting Mankosi.}

In Mankosi, hedges or fences around homesteads do not bound domestic routine and to run their homes women can take at least three times as many steps as most in the West [Bohannon 2007]. Mama NS, aged 52 years, for household of between ending on whether children are at school. Like some $25 \%$ of household of between ending on whether children are at school. Like some $25 \%$ of households her family catches drinking water in a barrel from a zinc roof of a "flat" (square building). But to collect water for washing and cooking she walks three times per day to a communal tap, $2 \mathrm{~km}$ from home, just after dawn, before lunch and then again at dusk. Once or twice a week and always on Friday, when she took 21,000 steps, Mama NS collects firewood, usually with others, from one of two forests $1 \mathrm{~km}$ and $3 \mathrm{~km}$ from home. She hand washes much laundry on Saturday and Sunday, as the children own just one uniform jumper and pair of trousers or skirt each, and must walk to and fro to collect water from the tap, and thus accumulated 20,000 steps. Mama NS takes fewer steps on Thursday, when, from 1:00pm to 4 :0opm she always walks, usually with friends, to the ladies church service, $2 \mathrm{~km}$ from home. Within her homestead Mama NS walks between gardens and different rondavals with modern kitchen equipment, a traditional grinding stone and cooking fires. Her walking is shaped by the season that affects what grows in each vegetable patch and by taboos, such as prescribing that she does not cross in front of the kraal where her husband's ancestors sleep in the day.

Teens and children also walk far to do chores and attend school. Mama NS's youngest, 15 yearold, daughter and eldest, 11 year-old, granddaughter walked over 1,00o steps just within their homestead cooking and cleaning at the weekend. Even Mama NS's $3^{1 / 2}$ year-old granddaughter, walked 8,000 steps helping her, in between playing indoors when it rained one day. Through walking the little girl assumes her social role, and one day walked 14,000 steps to pre-school with her friend, to the store alone, and to fetch water with her mother. In the week the older girls walked 14,000 steps to junior school, to afterschool classes, and in between to fetch water to wash their school uniform shirts. Catching the bus to high school saves another of Mama NS's daughters, aged 22 and in grade 12, some 13,000 steps, but it leaves at 5:45am and returns late so she has less time for chores. Despite all their walking the girls and young women also participate in netball, volleyball or athletics.

Men's walking varies more than women's. Some move cattle between kraals and common grazing land, lead donkeys that haul wooden sleighs, or carry sand from the beach (Figure 8). For instance, Mama NS's husband, aged 63 years, awakes at 4:30am to inspect his kraal and gardens behind his home for animal or human theft. Of the $40 \%$ of men in Mankosi who own cattle, most have only 3 to 7 cows; but Mama NS's husband had 32 that he takes, with his 47 goats, to pasture before walking back up the hill to tend a slash-and-burn patch in a forest $5 \mathrm{~km}$ from home. He returns home for lunch and rests for $1 / 2-\mathrm{hr}$, around $2 \mathrm{pm}$, before walking back down the hill to take cattle to kraals or to a warm area on the beach. He

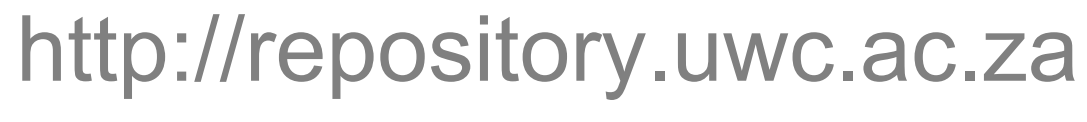


accumulated an average of 20,000 steps daily, across the week, but once a week he and his eldest son drive cattle to dip, so he walked 25,000 steps. Tata MM, aged 51, owns chickens and pigs but still walked 20,000 steps a day to tend his spinach, cabbage and carrots in plots in his garden and in the forest, and to the soccer pitch to watch or join his team training in the afternoon. Men spend longer in meetings, answering for their household's conduct or discussing politics in the shade of a hedge. Indeed, when Mama NS's husband was at a meeting he took half as many steps as usual $(10,000)$, and his sons tended his cattle. Men, more than women, sit drinking in shebeens and chatting on hills between homes. Tata NN, aged 47, for instance, practices "ilima" (making Xhosa beer) which he drinks with others so he can take as few as 1,000 steps a day. Actually, he averaged 8,000 steps a day but this was raised by the day he walked 20,000 steps when he caught crayfish and sold them to white homeowners.

Between 500 and 900 people live in each village in Mankosi, but the number is hard to verify. People move between villages and cities, for work and school while children may move between parents, siblings, half-siblings, grandparents, aunts and cousins in different homesteads. So, for instance, Tata MM (above) walked to help his mother, who cares for his younger brothers and half-brothers and her grandchildren in his former home, in the morning and again after lunch; and Mama NX, aged 43 years, walked 17,000 steps every day to care for eight children and other family members who live $2 \mathrm{~km}$ from where she stays.

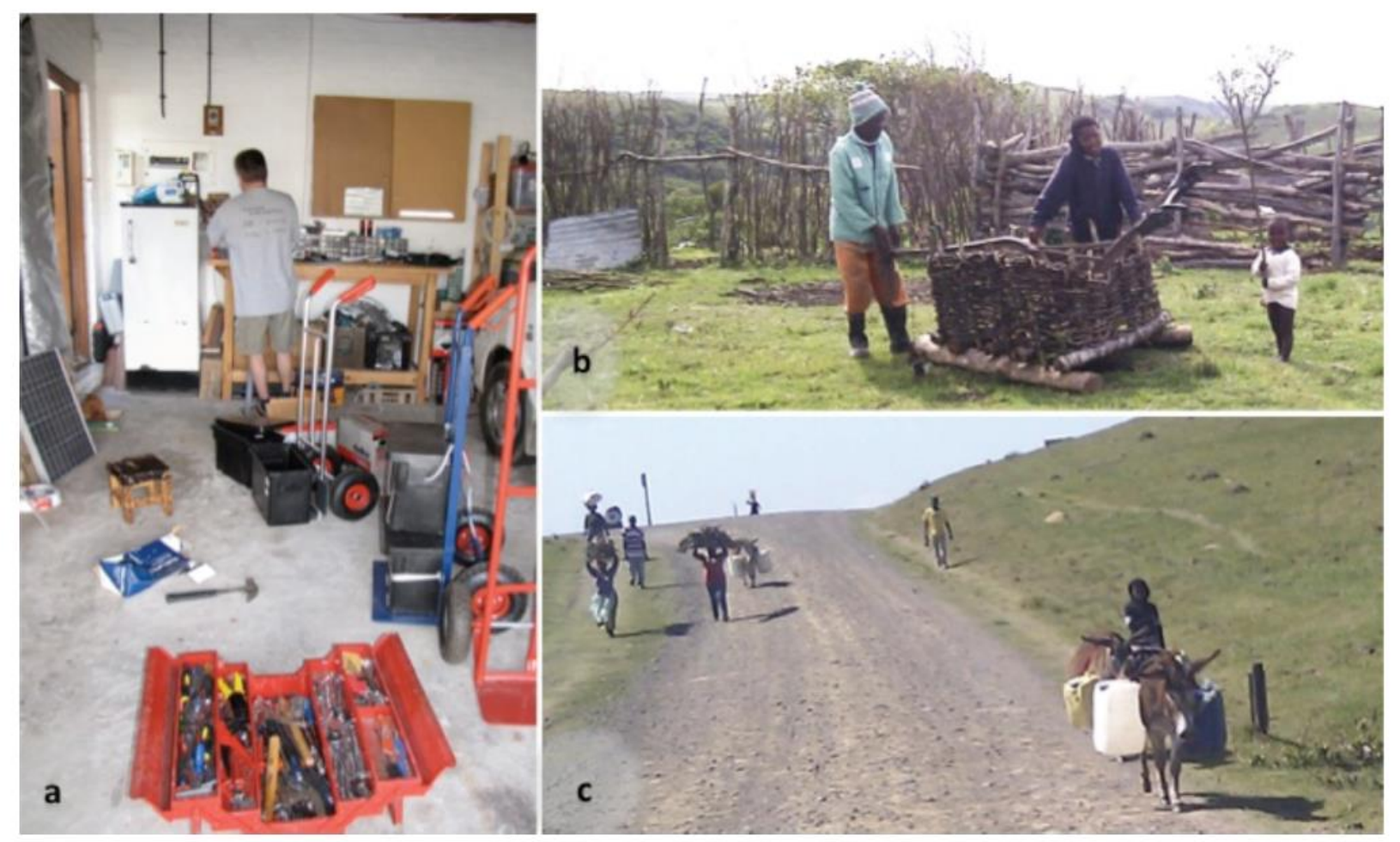

Fig. 8. While A3 designed the Solar Stations in a home in Cape Town (a) the Headman's family members and neighbors prepared a sleigh to carry harvests (b) and inhabitants of Mankosi walk (c). 

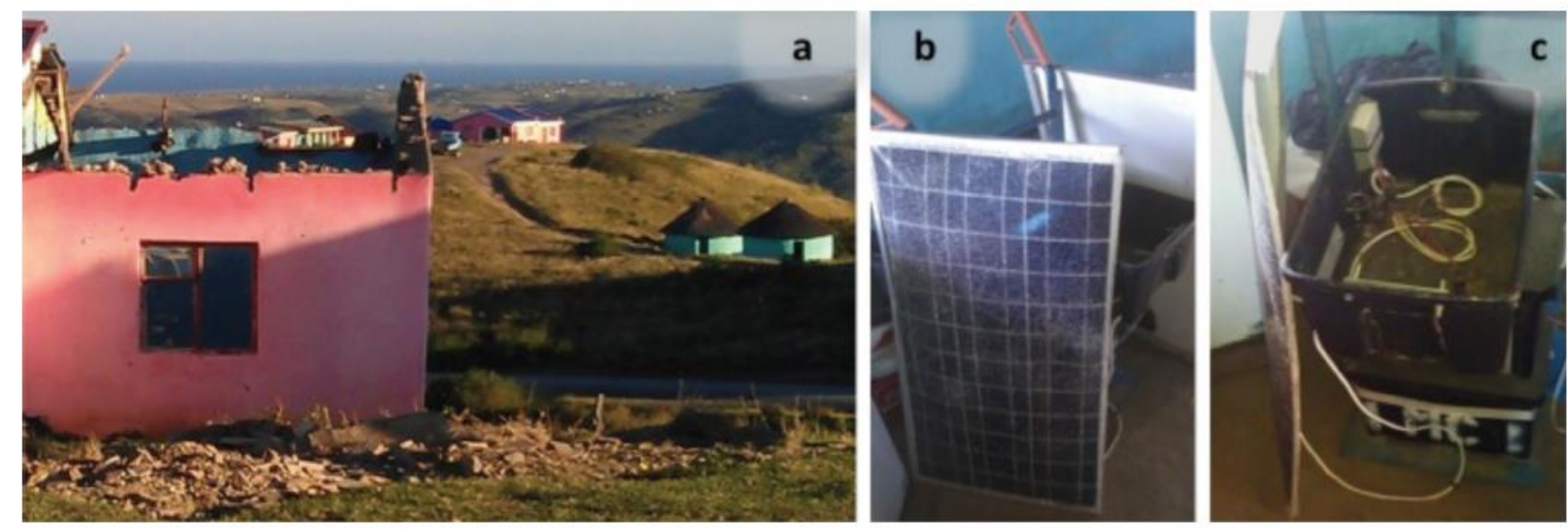

Fig. 9. Two years after initial deployment extreme wind and rain collapsed the roof of the building where the Headman stored the Station (a). Water and debris destroyed one of the panels (b, c).

\subsubsection{Walking \& Resource Use.}

Our ethnography and inhabitants' own recordings suggest that all subsistence practices involve walking, and other bodily work, and this contributes to parsimonious resource use. Households do not accumulate bills for centralized "utilities," flick switches, or store perishable food. Diet mostly consists of dried food (beans, rice, maize etc.) that involves fetching water and wood to cook in cast iron pots on fires, and tiny amounts of vegetables picked daily from gardens or bought at nes; and, 50\% of phone to deploying the Stations, recorded at least one day in seven when they did not use their phone at all. Inhabitants usually pay on average $20 \%$ of their regular outgoings to charge phones and buy "pay-asyou-go" airtime. They can go for over a week without charging and ensure their phones are fully charged, when they pay to charge, check feedback about batteries on phones and often switch them off. However, unlike Wyche and Murphy's [2012] interpretation of tactics to preserve charge in rural Kenya, in Mankosi a phone's power reserve at any time interconnects with other physical and social resources. People buy airtime coupons (marked up by $20 \%$ locally), when they can afford to when available locally, and make very short voice calls, usually at the cheapest times, and use free phone services rather than send SMS [Bidwell et al. 2011]. Further, they interact with phones only briefly when not in their homesteads, and which barely interrupts walking; switch phones off when they go to places without cellular network coverage, such as pasture and forests; and, often rely on intermediaries which involves walking. Around $35 \%$ of people (in our sample of people over 14 years old) did not yet own a cellphone, and the remainder had owned a phone for less than 5 years, many acquiring them since 2010. Prior to owning their own phones, men working away from their village, such as in a mine, phoned or sent Callbacks using another man's phone to someone in their village, who would walk to take a message or the phone to their wives. Textually and/or technologically illiterate inhabitants gain assistance in using phones, which again may involve walking; for instance, a young illiterate mother always waits for her teenage daughter to walk home from school to read messages and missed calls to her. Often practices of communicating with or charging phones reproduce patterns where children walk to run errands, take messages for their elders and, in the past, posted and collected letters at the store en route to school. 


\subsubsection{Familiarity \& Identity.}

Walking contributes to inhabitants' familiarity with each other, as epitomized by a friend's recognizable caricatures of others' gaits. This familiarity can act to minimize resource use, for instance, to appropriate cost-free phone services effectively and by using digital homonyms and coding systems [Bidwell 2011a]. It can also protect resources. People know all the families in their village and are often related by blood or marriage. Although some have reputations for pilfering, people tend to attribute stealing to tsotsis from beyond their villages (e.g., drivers repairing trucks in Ridge) and repeatedly said that the "community must work together" to address theft. This entwines with expectations that people's practices are visible, in fact one of the first phrases a foreigner learns from local people's questions is: "Where are you going?”. Inhabitants said that an unattended, coin-operated, self-service charging at a clinic or school would be prone to theft and vandalism and we (A1) had to insist in several situations that well-intentioned LRs should not insinuate that any project equipment could covertly record or track users. Unlike in urban areas, people often leave homes that are clearly visible to others unlocked, although spazas and established shebeens do have grilled counters and doors and barbed-wire fences. The Tribal Authority grants land to local people to build homesteads that, once fenced, are territories for which occupants are responsible and that others must respect. Being judged as having inappropriate intentions towards property or communal resources is met with severe traditional disciplinary measures and high social penalties; thus, we retrieved a stolen project phone buried in bushes out of view by agreeing not to disclose the thief's identity. Since walking plays a significant role in visibility it must also feature in the embodiment of "social risks" [Klemmer et al. 2006].

Walking features in performing identity. Consider how inhabitants associate status with a noticeable ability to support current and future family members. A man's wealth, for instance, is displayed as his cow walk around and/or in a prominent flat ough people also say flats are less comfy or maintainable than rondavals). Meanwhile, parents save in funeral plans that are widely deemed to offer meagre return but invest against the shame felt by descendants unable to offer hospitality at a funeral: overtly slaughtering and cooking an animal and erecting, in their homestead, a rented tent and a headstone. Ill health and early death is rife in Mankosi. Children's tiny physiques and distended bellies imply poor nutrition in Ridge and in just 18 months ten people, aged 14 to 75 years, died in different homesteads within $1 \mathrm{~km}$ of our (A1's) home. Many inhabitants consult a biomedical doctor just once a decade, despite health issues from skin infections, intestinal worms, cholera, TB and a HIV prevalence of 29\%. When someone dies, and also to prepare for other ceremonies, women bring large amounts of wood and water that they have collected, to the host homestead. Their walking in such practices of communal responsibility is visible.

Inhabitants' familiarity requires carefully managing both resources and their social ties and status. For instance, the few inhabitants who own solar systems or generators tend to charge others' phones or watch TV with others until batteries are flat or petrol runs out, but this is not just because they do not have a way to measure voltage. They must manage sociability, amidst cycles of exchanging favors, such as working the land together; borrowing/lending agricultural tools and money; jealousy; gossiping tongues; and, witchcraft (which, like HIV and intimate 
relationships, is not discussed openly). Some older inhabitants say "it's easier to eat money than cows," connoting that both bodily effort and social values associated with owning healthy stock, limit consumption. In fact dilemmas seem to arise when consumption involves less bodily effort or social value, such as to save personal digital and electrical reserves. Many feature-phone owners, for instance, found it difficult to choose what media to keep. Some, aware of different data stores, moved music to make space for other media, but not all had memory cards or knew how much media their phones could store so reluctantly deleted music they had listened to "enough" or was new, even if they liked it. A few feature-owners said they would listen to music even if they noticed their battery was low, but many said they prioritized calls so could not listen to music on their phones every day. One young man said "if I have a battery I listen to the music" in the evening but that at times he "worried" his battery would run out.

\subsubsection{Cooperation \& Concealment.}

Inhabitants refer to practices that are counter to collective interests in somewhat accusatory terms; for instance, they vigorously agreed that a person who insisted on charging when the Station's battery was low, in order to make an urgent call, was "aiming to destroy" the Station. Thus, many routines suggest inhabitants seek to avoid allegations about their nonconformance to communalism. For instance, while the Subheadman's wife clearly resented the Station in her home, she did not explicitly object about her lack of privacy or the demands of her husband's role. People also said that recording audio would "stop people lying" in meetings, which approximates to being held accountable, and the Headman refers to the tablet as his "witness" [Bidwell and Siya 2013]. Yet, while it seemed that the Tribal Authority sought to show that their decisions were transparent and based on consensus, inhabitants also spoke of gifting them to obtain a local job opportunity. Indeed, ambiguity between concealment and disclosure was apparent when inhabitants spoke in consecutive meetings about obscuring an illicit income-generating crop and about increasing voter registration to gain another ward and join in democratic elections.

Routines of visible cooperation exist alongside routines of concealment. For instance, family members eat a chicken together after dark to avoid sharing with those not residing in their homestead. Actually, even in the electricity-free darkness people protect privacy. One inhabitant said he concealed nocturnal rendezvous by disguising the sound of his footsteps and sometimes teenage lovers on the road swiftly switched off shlight as we approached. Phone owners said that there were no disadvantages to the privacy phones enabled, and that access to phones had changed their communication patterns so that now they used mixtures of Callback, buzzes, vocally "shouting-out," and walking to another homestead depending on their reason to communicate.

Expectations of visibility, conformance to roles and personal needs can jostle within families. Consider how the Subheadman's wife did not contest her husband's decision, despite her discomfort with the Station in her home, because he "is the owner of the household." Young people mentioned their sense of security in sharing a bed with other same-sex family members but also that they plan their privacy in order to use phones in ways that older people in their

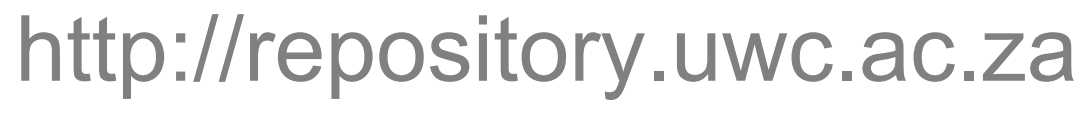


homestead do not approve. Growing up in close proximity contributes to bonds; for instance, in many homesteads at least one rondaval is furnished with beds and kitchen equipment but while some inhabitants expressed satisfaction about the duties that come with these bonds, others expressed mixed feelings. On the one hand an LR who, as the eldest son has inherited responsibility for siblings in education, unmarried and widowed sisters, and their children, said, contentedly, that he gave his only warm coat to his brother studying in university; while on the other, a well-remunerated student slightly resented sending money home from a city to assist in siblings' education.

\subsubsection{Belonging Embodied in Walking.}

Inevitably inhabitants experience a range of emotions as they walk along familiar paths, amongst familiar humans and non-humans. Some affects specifically relate to the practice during which they walk; for instance, a man may feel a sense of worth as he herds his cattle and a woman fear in a forest when alone and perhaps pleasant anticipation of the weekend, or the drudgery it entails, as she carries her fuelwood home. Inhabitants also feel a sense of belonging. Some never go to town, many mention the dangers of urban townships and most migrants return to the village they call home. This sense of belonging involves social connections that are embodied by the corporeal walking body. People develop a pace that endures the demands of long distances in the hilly terrain and entwines in routines of copresent talking. They mentioned that walking with someone else makes the journey easier; females collect water together and chat as they walk, while buckets fill, or with those they pass laundering at dams. Women rarely carry anything in their hands as they walk, but rather on their heads held high and faintly tilted, able to greet those they pass. We have noted before that rural Africans manage time in relation to other people [e.g., Bidwell et al. 2011b; Bidwell et al. 2013] and in Mankosi this is affected by walking. Actually, we (A1) were regularly teased about our hurried, Western march when we felt we were 'running late', even though we knew meetings and research activities rarely started at a scheduled time, and we might wait hours for people to arrive and then half an hour more as they greeted each other or drank tea after their long walks. People embody the pace of walking and talking from early in life: carried, swaddled in blankets, on women's backs while they walk between homesteads and between rondavals, call to each other and sometimes, sing. Gill [2012] proposes that rhythmic synchrony of bodies and voices enables "being together." We all have rhythms in breath and gait that we tune with timing of syllables and pauses in speech; and Gill [2012] suggests that this self-synchrony enables us to adapt our rhythms to others in many ways. Perhaps, shared bodily rhythms in walking contribute to local skills in harmonizing song. Whatever way, though, movements, as Ingold and Lee [2006, p. 2] write, are "rhythmically resonant with the movement of others around us-whose journeys we share or whose paths we cross."

Enduring connections between people are not just embodied in the corporeal walking body but also in the spatio-temporal trace, or path, that is forged or followed by links connect the living and also the living to the dead as many inhabitants can trace their ancestry over 5 generations across Mankosi and neighboring districts. Some of these links manifest concretely, in ancient paths trodden by cows and in ancestors' graves in homesteads or places that were once homesteads. Some links manifest in undertaking the same practices 
in the same places, such as gathering wood as a woman's female line and in-laws have done before. Some links are reproduced in practices of praying, dreaming and ritualizing that recognize that ancestors are agents in the present and adjudicators and protectors of the living. Some links between the living, and between the living and the dead, manifest in naming practices. All inhabitants have both clan and family names, which may be an ancestor's first name or describe a local event or natural feature (e.g., a forest); and a birth name, which is unique in the parent's villages and can signify siblings' birth order; and, sometimes nicknames related to local anecdotes (e.g., Tata Kingsize) or English names they adopt to aid foreigner's pronunciation. Further, men gain circumcision names, when they spend a month walking in the forest with their peers. Some women gain a new first name on customary marriage, which occurs when future male in-laws capture them when they walk for an errand, usually by prior agreement, and then a period confined to their husband's homestead except to fetch water and wood. Thus names are not merely attributes that identify autonomous, entities but, rather, arise in relations of practice that occur along converging metaphoric and actual paths. They convey links between inhabitants and between inhabitants and their ancestors, like a story does, and people use this information; such as to record names in Station logs or to understand cost-free services, for instance, an older man said that the formality of a clan name in a Callback might express that the sender was "really desperate."

\subsubsection{Experiencing the World's Continual Coming into Being.}

Walking makes the environment readable to humans and non-humans. The path traced by walking yields a spatial legibility; for instance, when people herd other cows along with their own, each set knows to leave the main gravel track at the path to their owner's kraal. Paths traced by movements also participate in a temporal legibility. People sense time through non-human movements, like the sun's travel, cockerels and birds stirring and roosting, meanwhile non-humans sense people's movements, for instance, within two days goats learn the time at which their owners will come to return them to the kraal. Spatio-temporal traces vary across the day and across the seasons. After nightfall, and when it rains, the paths that inhabit Mankosi contract. Some people attend church services, their song carrying into the night; others drink at shebeens, where noisy generators power a light bulb and, maybe, a CD player, especially on pension day or weekends. Normally, though, inhabitants are in their homes after 8:0opm, a paraffin lamp flickering dimly here or there, but most asleep, avoiding the darkness and its ghosts. People try to stay indoors on rainy days, which are frequent between October and March, to avoid slipping down muddy hills or crossing huge puddles across gravel roads. In winter, men make mud bricks and women gather grasses. Those with successful gardens dry and store maize, so two weeks prior to harvest women collect more wood in advance of when they will be too busy to gather it. Meanings emerge in the tempo of movements; for instance, in the daytime homestead owners are responsible for keeping others' animals from languidly entering their gardens. At night, however, inhabitants must keep their own animals in kraals and pay a fine to the owner of a garden if one of their own animals enters it. 
Inhabitants' bodily effort, in producing and using resources, and proximity to the transitions of materials probably makes them more acutely aware of actions that affect the environment than, say, low-income households in industrialized regions [Dilahant et al. 2009]. Peoples bodies transform the fabric of their of their "natural" setting for food, and for shelter and protection. They surface floors with fresh cow dung, to keep homes warm and dust free; gather grasses that they, or others, use to thatch roofs and make into brooms, mats and ropes; collect wood for fuel and fencing; put stones on zinc roofs to hold them down in the wind; make mud into bricks; and, apply clay to protect faces from the sun. Inhabitants feel their involvement in the "world-in-formation" [Ingold and Lee 2006, p. 2], often walking shoeless, even in winter, to grip grassy slopes and convert grass to paths to muddy mires. Their bodies feel their inseparability from the environment, such as the effect of rainfall patterns on the food they produce and the land's re-assimilation of the homes and kraals that they constantly build and repair.

Certainly, many practices in Mankosi would be deemed "green" according to common narratives [Shove 2003]. People shop in relative bulk on monthly pension day in spazas or in Mthatha, if they can afford the bus or a canopied Coupe Utility taxi in which they sit, cramped with over 15 people, and charge their phones along the way. They buy few goods in aluminium or plastic; limit detergents to laundry soap; recycle water (for gardens) and other items (e.g., using oil containers for storage, candle wax to start fires); and, only $10 \%$ of homesteads own freezers, powered by pressurized gas tanks delivered monthly on trucks, in which they store beer and "cool drinks" (Coca-Cola, ginger beer) to sell in shebeens. However, practices are uninfluenced by policy discourse and national campaigns about global warming or biodiversity, or even government conservation projects that employ some inhabitants as laborers to curb invasion by non-native species at the river mouth and clear up coastal trash. People throw cans and glass in the forest or burn them with paper in shallow pits, often next to crops or medicinal herbs; they catch illegal undersized fish in the ocean, sometimes hunt "bush-meat" (e.g., monkeys); and, deplete the forest by gathering wood, cultivating crops and grazing goats.

Inhabitants value their "natural" setting and notice changes, such as the forests' rapid depletion and ancient batteries remaining in the soil, but they are more sensitive to the "relational processes" [McCarthy and Wright 2004] of community and personhood than of ecology. People recognize transitions of materials; for instance, older or more technologically literate women said power belonged to the battery or to the sun after we outlined the process of solar energy transduction. Yet it seems meanings about social relations eclipse those of the inseparability of the environment and living bodies. So, younger, less technologically literate, women decided that residents all owned the power in the battery much as water, collected from a roof in a barrel, "belonged to" the owner of the roof or the barrel. We speculate that people feel their corporeal experience, in the world's continual "coming into being" [Ingold 2011] most acutely through relations between the living, and between the living and the dead. They ascribe meanings about ancestors to natural elements, such as the forest, animal species and weather. Wind sounds on a roof can be a sign of malevolent spirits, a high-pressure stillness can denote the passing of an ancestor, and some practices specifically respect elements associated 
with totems (e.g., animal species, ocean life) with clan and family names. Perhaps the importance of signs about ancestors explains why, without prompting by others (e.g., A1), operators started to record the wind in their Station logs; incessant at times and intense enough to blow dust into eyes and spectacles from our face.

\section{Literacies in sustainability}

Inhabitants' practices in using the Stations interconnect with the many ways that their walking creates, expresses and "reads" relationships in their social and physical environment. By walking, their bodies acquire literacies in the traces and rhythms that walking produces and reproduces. Thus, we posit that walking was involved in the literacies that grounded various people's perspectives on sustaining the Stations. We do so by first considering local perspectives in terms of two analytic categories, gender and age; and then reflecting on how walking, or not walking, shaped knowledge in designing the Stations.

\subsection{Gendered Walking}

Accusations that operators prioritized charging their friends' phones came from men who had been unable to charge at Ridge's Station and we speculate that this perspective relates the divergence of their own and women's daily movements to, from and around Ridge Station, and their greater access to phones in general. The proportion of men and women who charged at Ngcobo seems consistent with the greater number of women in Mankosi, since men are more likely to work in cities or mines, but that relatively fewer women than men own cellphones (56\% of females, $76 \%$ of males) and male phone owners spend more on airtime than females and make more calls [Bidwell et al. 2011a]. Both men and women brought more than one phone to charge in Ngcobo, but at Ridge women brought the phones of their households, including their husbands' phone, and rarely owned more than one phone themselves. Both women and men less frequently brought other family members' phones to charge at Ngcobo. The main differences were that men visited Ngcobo and women visited Ridge Stations more frequently overall and of those charging regularly men charged more often than women at Ngcobo.

Each site had a different gendered character. Women operated Ridge Station and were visible doing chores, but men operated Ngcobo Station near the office where men, and some women, come for business, and over $15 \mathrm{~m}$ away from the places where the Headman's wife does chores. Prior to launching the Stations, older men emphasized their own use as they contribute most to local governance. However, the times of Ridge Station's operation were less compatible with men, for instance, one said: "whenever I come they say it's full, and because I don't have time I have to go to another place"; and men more than women mentioned that if their phone was uncharged they would miss calls and sometimes they were unable to find, by walking in villages, the person they sought. Thus, we speculate that men's greater access to phones, time spent talking together and greater distance from homesteads during Station operating hours, meant they were less likely than women to notice movements to, from and around Ridge Station. Further, their literacy in reading Station routines was influenced by local narratives about male territory.

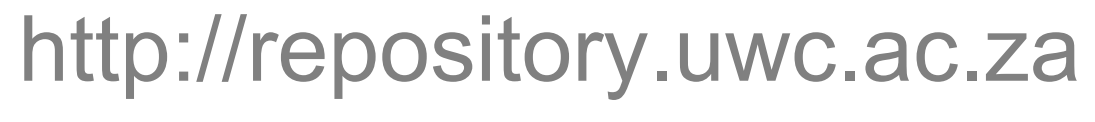




\subsection{Age and Sustaining Community}

Children often brought others' phones for charging, but younger phone-owners, particularly those aged under 22 years, had less access to Ngcobo than Ridge Station due to the formality associated with the Headman's homestead and operators' enforcement of rules. At Ngcobo the younger operator, who lived most locally, sought to affirm that people must come in person to charge phones but found it difficult to assert other rules when older people dropped off phones because of authority protocols. Further youth are not at ease with socializing at the Headman's homestead and Elders said that younger people's phones require charging more often, since they "played" on chat services and games and listened to music. Yet, the gap between young and old profoundly affects the potential for environment and community sustainability. While older people seem better able to manage resources over time and collectively moderate resource use Mankosi also has a "skip generation" problem: the population declines dramatically between the ages of 20 and 44 years because people of parental age are most likely to have died from illness or work far away.

\subsection{Legible Relationalities}

Our modest theory about how walking tunes perspectives on using the Stations leads us back to reflecting on the legibility of relationalities in decisions in sustainable design. The domestic and research routines of inhabitant researchers (A1, LRs) associated using electricity with local patterns of walking, communicating and 'natural' phenomena, such as weather. This sensitized us to discord between research and design schema and local ways of understanding, knowing how, interpreting, feeling, wanting and avoiding. Designers and researchers draw on certain schema, such as those about time or land, in gathering, and representing data and responding to life "out there" in others' regions [Taylor 2011]. Dourish and Bell [2011] refer to Scott's [1998] description of a "panoptic legibility" that is applied in making sense of diverse settings. This "view from without" is characterized by dislocation and distance so, for instance, external researchers (A8, A9) observed at discreet geographic milieu to accumulate data in short visits, interviewed inhabitants indoors to ensure high quality recordings and spent hours in rooms with electricity to secure the valuable data. These practices made their knowledge portable in particular ways [Irani et al. 2010] but the data they produce differs from the data that occurred when we (A1, LRs) interviewed, proposed and decided along tangible and metaphoric paths, enmeshed in the familiar furniture of rural life.

Ingold [2007, 2011] refers to the upward integration of discretely, sampled data, into comprehensive representations as "occupant" knowledge. He argues that occupant knowledge is founded upon a categorical distinction between the mechanics of movement and the formation of knowledge, or between locomotion and cognition [Ingold 2007, 2011]. That is, occupant knowledge is disembodied from the local paths along which that knowledge was forged and separates the moving corporeal body from the traces bodies inscribe and read in movement. As a result, occupant knowledge foregrounds the intersections of mobile elements and not the relations that occur as we continuously go along in life. 
Informing design with occupant, rather than "inhabitant" knowledge [Ingold 2007, 2011] can neglect the knowledge and know-how that sustains poor communities. Consider, for instance, Wyche and Murphy's [2012] approach to designing for phone-use in low-electricity conditions in rural Africa. They generated design implications from data gathered in six weeks at six distant, rural sites in Kenya, which precludes engaging with local relations in local terms [Irani et al. 2010; Taylor 2011]. Although they aim to inform designing for "the bottom of the pyramid", many of the 23 people that Wyche and Murphy [2012] interviewed were selected via mutual contacts in the US, had paid jobs and owned transport. They interviewed in English, mostly sole owners of phones and mostly individually. This data inherently privileges nonlocal categories and orderings [Taylor 2011]; nonlocal semiotics in interactions and narratives about settings and causality [Merritt and Bardzell 2010]; and a single-user model of use [Dourish and Mainwaring 2012]. It omits most aspects of practices that sustain the poorest in rural Africa and surely link to phone use and charging and to more locally sustainable alternatives.

Wyche and Murphy [2012] upwardly integrated data from distant sites, which they reached by vehicular transport, and write that this integration was shaped by their own practices with phones. Our habitual practices fashion our bodies and mediate our literacies. This includes the fashioning of bodies by practices of moving as well as disciplinary knowledge practices [Birtchnell 2012] and movements inherent in these [Irani et al. 2010]. Hui [2012] explains how material objects, such as phones, are mutable and their use is inseparable from the work of moving them; so, even when we temporarily adapt to constraints on electricity we do so with bodies fashioned by, and carrying, our more habitual practices of using phones and producing knowledge for HCI. Moving an urbanized or Westernized body along at a rural African pace may expose qualities obscured, but pertinent, to life in the West, but also eclipses meanings that inhabitants embody [Bidwell and Browning 2010]. For instance, a walking pace of life might offer relief to a body burned-out from business [Sengers 2011] until that same body must walk two hours to reach the nearest clinic, as Mankosi inhabitants do. Without similar repetitive encounters in the same specific set unaware of specific sets of connections on which local practices depend.

The meanings that emerge, amidst Mankosi's inhabitants' own, and their ancestors' footsteps, differ from those embodied in the ways Westerners inhabit households and contributes to incompatibilities between technologies and the ways inhabitants know, perceive, feel and want. We designed the first versions of the Stations while inhabitants decided on deployment sites, so our decisions aimed to afford flexibly siting, moving, using, protecting, repairing and customizing the Stations. We were constantly aware of trying to subdue our routinized knowhow about what makes a "good" system [Marsden 2008], yet we embedded certain relationships: between damage and repair; between artefacts and mobility; and between portability and security. These relationships interacted with the reality in Mankosi. So, although we designed our system to be repaired, unlike solar chargers used in Kenya [Wyche and Murphy 2012] we did not account for interactions between breakages and the distance to town, or the unreliability of postal services. Importantly, we could not predict the effect on the Stations' sustainability by interactions between the spatializations we embedded in their 
design and local spatializations that reproduced social relations. Thus, we have learned that it is probably impossible to determine what sustainable practice means a priori, and certainly not from the short-term studies and deployments that typify designing for Africa's rural poor.

\subsection{Parochial Knowledge Practices Limit Sustainable Design}

HCI is becoming aware of how the research encounters we set up and the artefacts we design and focus upon, conceal our power to authorize certain perspectives [Dunne and Raby 2001]. Recently authors have drawn on postcolonial theory to articulate the poli- tics embedded in designing for "developing" regions (e.g., [Irani et al. 2010; Merritt and Bardzell 2010; Taylor 2011; Dourish and Mainwaring 2012]). From this perspective, we firmly support Wyche and Murphy's [2012] claim that HCI overemphasises devices and applications that consume too much electricity, but we also notice that the rest of their design implications are complicit with the politics that produce unequal access to electricity and markets for nonlocal products. In writing that "large-scale formal rural electrification is unlikely to extend to remote locations," Wyche and Murphy [2012] join the many who "systematically avoid confronting the actions of large-scale actors, such as governments and corporations as causes of the socio-economic conditions they seek to remedy" [Irani et al. 2010]. Wyche and Murphy [2012] do not mention established and award-winning solar enterprises in Kenya (e.g., Africa Innovation Foundation [2012]), but rather overseas products. They do not translate the ingenuity and craft skills of Kenyans that they observed to, say, affordable self-assembly of photovoltaic cells arrays. Nor do they recognize potential compatibilities between routines of rural subsistence and increasingly viable, organic solar cells that offer "Earth-abundant", energy solutions with fewer of the socio-economic and environmental impacts that come with mineral extraction in Africa [Irani et al. 2010].

Wyche and Murphy's [2012] approach exemplifies knowledge practices that inform design for rural Africa by upwardly integrating data generated in a few interviews focused on technological artefacts and their use. These practices produce perspectives that are "implicitly partial, unrecognizingly narrow and unreflectively local" [Dourish and Mainwaring 2012] to occupiers not inhabitants. They do not promote more sustainable alternatives to the ways that occupiers make inhabitants consumers of their products [Irani et al. 2010]. Our main concern in this article, however, has not been to articulate the binaries of domination and submission in a specific design. After all, Mankosi's inhabitants subverted design strategies just as much as de Certeau's pedestrians resist by moving in the topographic stages built by city planners [Dourish 2006]. The Headman, and everyone else, ignored their own rules by sending children, taking several phones and arriving at Stations outside of operation times. Yet, these practices were not some willful defiance since inhabitants displayed a routinized conformance to collectivity and hoped that we (A1) would arbitrate their practices. Rather, our concern is primarily that the parochialities of HCI's knowledge practices limit detecting and translating complex relationalities that are most pertinent to sustainable design.

\section{Integrating knowing along into knowledge about sustainability}

Integrating separate observations from multiple discrete loci enables comparing the planet's systemic status across time and space. But the panoptic legibility that reads "universal facts" 
[Dourish and Mainwaring 2012] in diverse environments and the occupant knowledge produced by upwardly integrating these "facts" cannot depict the meanings and infrastructures produced by inhabiting. It is hardly surprising, then, that representing information about resource use sampled around temporal and/or spatial points in discrete practices masks and legitimizes certain types of consumption, often in the interests of profits of large-scale actors. Strengers [2011], for instance, explains that householders in the West are not deterred from practices they consider nonnegotiable and normal by "in-home displays" that aim to encourage minimizing water and energy use. She also explains householders may respond to feedback from in-home displays by altering patterns of consumption without changing cumulative resource use. This may help utilities providers to balance supply load but does not reduce their gross supply or its environmental impact.

Contemporary knowledge schema, in general, tend to reify "things" from practices [Stengers 2000], and in design this often means that purposes, goals, objects, and locations subsume the continuous, dynamic of knowing, operating, using and experiencing as we go along. Sustainable design decisions need to involve the knowledge and know-how that is embodied along everyday paths and the relationalities that occur and configure exchanges between bodies and the social and physical fabric in which bodies move. However, we encounter significant challenges when we try to avoid assembling data through a "surveyor's walk", if indeed, as Ingold says, the surveyor "does walk, rather than take a vehicle" [Ingold 2007, p. 88]. Conceptualizing behavior as practice, rather than purposes or social norms, has shifted focus to movements. Further considering the multiple enactments that objects assume in mobility [Hui 2012] can stir us to reassess knowledge practices that delineate according to disjoint classifications, such as goals or tasks.

We found that insights about inhabiting that are "alongly integrated" [Ingold 2011, p. 173], sensitized us to relationalities in Mankosi's social and physical setting that can better tune the space for sustainable design. We (A1, LRs) felt the inclines of hills and potholes in tracks that make sleighs and donkeys more robust than wheels on carts to carry loads; and, that might also tempt a person to dump toxic spent deep-cycle batteries in gardens. Our bodies battered by strong, often incessant winds, our attitudes dampened by cloudy and rainy skies, experienced a cost of solar power that radically differs from those who decided against a more monetarily expensive hybrid with micro wind turbines. A1's body accustomed to the land and our rhythms attuned to inhabitants patterns' so we noticed the incongruence of trudging through mud to fix Stations (e.g., Figure 4(c)) with local routines when it rains. At the same time A1's movements became normal to inhabitants or, in other words, walking participated in our sociality and performed in our social bonds that, in turn, shaped our electricity access and use. Consider, for instance, submitting this article. Every month or so in the Spring and Summer severe storms cut off electricity to the NGO where we (A1) walked to charge computers and this occurred the day before the deadline for this article. However, by saving his pay from his work in co-ordinating our research, A2 afforded a petrol generator, which he eagerly offered to enable us to submit this article on time. Thus our (A1's) walking not only exposed relationships between sociality and the environment, that we may not have detected otherwise, but also enmeshed us in local relationalities which may not have detected 
otherwise, but also enmeshed us in local relationalities which had consequences for expressing legibilities that matter to locally sustainable design.

Responding effectively to practices can help to moderate their systemic effects on the environment [Birtchnell 2012]. Consider, for instance, how inhabitants' everyday routines might alter when access to electricity arrives in the next few years. Currently, no one in Mankosi steals mains electricity, despite pylons along the main gravel road that serve visitors who own or rent cottages along the coast. When inhabitants have domestic electricity they might learn more about national narratives that attribute power cuts and load shedding strategies to electricity theft. Stolen electricity is equivalent to the output of a major coal-fired power station or $10 \%$ of South Africa's 36 oooMW net demand. However, while inhabitants might hear about campaigns to tackle illegal cable connections and meter modifications, at the same time their contracted domestic paths and altered visibility would make concealing theft easier. We certainly do not defend continued exclusion of Mankosi's inhabitants from access to electricity to solve this paradox, rather we advocate that research and design must account for sociality when we intervene and, for most people of Earth, sociality is profoundly about walking. Theft has increased with electrification in "developing" regions, and we surmise that a shifted balance between different types of mobilities, such as between walking and using cellphones, might have cumulative effects on sustaining environments and communities.

\section{Conclusion}

We have described practices and perspectives that emerged in deploying community-based, solar powered cellphone Charging Stations. We hope this will promote wider acceptance that we cannot assert what sustainable practice means a priori in any intervention or by interpolating from data sampled at discrete points according to the universalizing schema that typify research "out there." Our going along in the settings that constitute our lives creates both the environment itself and our knowledge of it, concretely, intangibly and ideologically. In this article, we have shown how walking interconnects routines in using, storing, sharing and sustaining resources, and proposed that detaching practices from bodies and their paths limits solutions. We advocate a more "alongly" integrated approach to gathering data on practices, and argue for relaxing our grip on point-based schema in relating resource-use to sustainability. Walking contributes to ways of understanding, feeling, wanting, avoiding and using things, and to the rhythm of the social and physical fabric of all aspects of life. Along the way bodies acquire literacies in routines that make certain relationalities legible, thus we propose that engaging with these relationalities can expand the scope for designing to sustain environments and communities like Mankosi.

\section{Acknowledgments}

We thank all inhabitants of Mankosi, community leaders and TransCape. We are extremely grateful to three anonymous reviewers for their diligence, insight, and provocation, to James Pierce and Yolande Strengers for their encouraging feedback, to Ann Light and Margot Brereton for literature tips and to Mark Rouncefield and Jofish Kaye for comments on an earlier manuscript. A1 also wishes to thank Mounia Lamas for her integrity and understanding during aspects of this work and Paula Kotze, her mentor at CSIR-Meraka, whose 
unfailing support meant A1 not only walked, but learned to drive and had the to freedom to "fly"! Finally, and very affectionately enkosi khakhulu: Bongi, Kholeka, Mapru, Sibongile, Lusy, Roico, Thumeka, Nomphello, Azola, Neliswa, Thatiswa, Pedro, Nelsie, Maddy, Andre, Domi, Roger, Judy and Stevo: Ndiyabulela kakhulu ngempatho endenze ndaziva ndikhuselekile kwilali yenu nangokundifundisa ukunimamela. 


\section{References}

ADEY, P. 2008. Airports, mobility and the calculative architecture of affective control, Geoforum 391, 438-451.

AFRICAN NNOVATION

FUND.

2012. www.africaninnovation.org/newsviews/news/article/?txttnews\%5Bttnews\%5D=40\&c Hash=ce8740098e7086fc6a4f3744b9f1470b.

BERGSTROM-LEHTOVIRTA, J., OULASVIRTA, A., AND BREWSTER, S. The effects of walking speed on target acquisition on a touchscreen interface. In Proceedings of the 13th International Conference on Human Computer Interaction with Mobile Devices and Services. 143-146.

BEST, M., SMYTH, T. N., ETHERTON, J., AND WORNYO, E. Uses of mobile phones in postconflict Liberia. Inf. Tech. Int. Develop. 6, 2, 91-108.

BIDWELL, N. J. 2009. Anchoring design to rural ways of doing and saying. In Proceedings of the International Conference on Human-Computer Interaction. Lecture Notes in Computer Science, vol. 5726, 686-699.

BIDWELL, N. J. 2010. Ubuntu in the network: Humanness in social capital in rural South Africa. Interactions 17, 2, 68-71.

BIDWELL, N. J. AND BROWNING, D. 2010. Pursuing genius loci: interaction design and natural places. Personal Ubiq. Comput. 14, 1, 15-30.

BIDWELL, N. J., LALMAS, M., MARSDEN, G., ET AL. 2011a. Please call ME.N.U.4EVER: Designing for 'Callback' in rural Africa. In Proceedings of the International Workshop on Internationalisation of Products and Systems.117-138.

BIDWELL, N. J., REITMAIER, T., MARSDEN, G., AND HANSEN, S. 2010. Designing with mobile digital storytelling in rural Africa. In Proceedings of the SIGCHI Conference on Human Factors in Computing Systems. 1593-1602.

BIDWELL, N. J., REITMAIER, T., REY-MORENO, C., RORRO, Z., SIYA, M., AND DLUTU, B. 2013. Timely relations in Rural Africa. In Proceedings of the IFIP 12th International Conference on Social Implications of Computers in Developing Countries (WG 9:4).

BIDWELL, N. J. AND SIYA, M. 2013. Situating Asynchronous Audio in Rural Africa. In Proceedings of the International Conference on Human-Computer Interaction. Lecture Notes in Computer Science, vol. 8119, 36-53.

BIDWELL, N. J., WINSCHIERS-THEOPHILUS, H., KOCH KAPUIRE, G., AND REHM, M. 2011b. Pushing personhood into place: situating media in the transfer of rural knowledge in Africa. Int. J. Hum.-Comput. Studies 69, 10, 618-631.

BIRTCHNELL, T. 2012. Elites, elements and events: practice theory and scale. J. Transport Geography 24, 497-502.

BOHANNON, R. W. 2007. Number of pedometer-assessed steps taken per day by adults: a descriptive metaanalysis. Physical Therapy 87, 12, 1642-1650.

BOURDIEU, P. 1990. The Logic of Practice. Stanford University Press.

BRERETON, M. AND GHELAWAT, S. 2010. Designing for participation in local social ridesharing networks: Grass roots prototyping of IT systems. In Proceedings of the 11th Biennial Participatory Design Conference. 199-202. 
BRYNJARSDO TTIR, H. AND SENGERS, P. 2009. Ubicomp from the edge of the North Atlantic: Lessons from fishing. In Proceedings of the ACM International Conference on Ubiquitous Computing.

BUSCHCER, M. AND URRY, J. 2009. Mobile methods and the empirical. Euro. J. Social Theory 12, 1, 99-116.

COCKS, M. L., DODD, T., AND VETTER, S. 2012. 'God is my forest'-Xhosa cultural values provide untapped opportunities for conservation. S. Afr. J. Sci. 108, 5/6.

CRESSWELL, T. 2010. Towards a politics of mobility. Environ. Plan. D: Society Space, 28, 1, 17-31.

DILLAHUNT, T., MANKOFF, J., PAULOS, E., AND FUSSELL, S. 2009. It's not all about "green": Energy use in low-income communities. In Proceedings of the ACM International Conference on Ubiquitous Computing. 255-264.

DOURISH, P. AND MAINWARING, S. D. 2012. Ubicomp's Colonial Impiulse. In Proceedings of the ACM International Conference on Ubiquitous Computing. 133-141.

DOURISH, P. 2001. Where the Action Is. MIT Press.

DOURISH, P. 2006. Re-spaceing place: "Place" and "space" ten years on. In Proceedings of the ACM Conference on Computer Supported Cooperative Work. 200-308.

DOURISH, P. AND BELL, G. 2011. Divining a Digital Future: Mess and Mythology in Ubiquitous Computing. MIT Press.

DUNNE, A. AND RABY, F. 2001. Design Noir: The Secret Life of Electronic Objects. August/Birkhauser.

FROHLICH, D., ROBINSON, S., EGLINTON, K., JONES, M., AND VARTIAINEN, E. 2012. Creative cameraphone use in rural developing regions. In Proceedings of the International Conference on Human Computer Interaction with Mobile Devices and Services. 181-190.

GILL, S. P., Rhythmic Synchrony and Mediated Interaction: towards a framework of rhythm in embodied interaction. AI \& Society 27, 111-128.

HUI, A. 2012. Things in motion, things in practices: how mobile practice networks facilitate the travel and use of leisure objects. J. Consumer Culture, 12, 2, 195-215.

IFAD. 2011. Rural poverty report 2011, International Fund for Agricultural Development.

INGOLD, T. 2007. Lines: A Brief History. Routledge.

INGOLD, T. 2011. Being Alive: Essays on Movement, Knowledge and Description. Routledge. INGOLD, T. AND LEE, J. V. 2006. Ways of Walking. Ashgate.

IRANI, L., VERTESI, J., DOURISH, P., PHILIP, K., AND GRINTER, R. E. 201. Postcolonial computing: a lens on design and development. In Proceedings of the SIGCHI Conference on Human Factors in Computing Systems. 1311-1320.

KLEMMER, S., HARTMANN, B., AND TAKAYAM, L. 2006. How bodies matter: five themes for interaction design. In Proceedings of the SIGCHI Conference on Human Factors in Computing Systems. 140-49.

LAW, J. 2004. After Method: Mess in Social Science Research. Routledge.

LEE, J. AND INGOLD, T. 2006. Fieldwork on foot: perceiving, routing, socializing. In Locating the Field Space, Place and Context in Anthropology, 67-86.

LEVINE, R. 1997. A Geography of Time: The Temporal Misadventures of a Social Psychologist, or How Every Culture Keeps Time Just a Little Bit Differently. Basic. 
MARCUS, G. E. 1995. Ethnography in/of the world system: the emergence of multi-sited ethnography. Ann. Rev. Anthropology 24, 95-117.

MARSDEN, G. 2008. Toward empowered design. IEEE Computer 41, 6, 42-46.

MCCARTHY, J. AND WRIGHT, P. 2004. Technology as Experience. MIT Press.

MERRITT, S. AND BARDZELL, S. 2011. Postcolonial language and culture theory for HCI4D. In Proceedings of the SIGCHI Conference on Human Factors in Computing Systems, Extended Abstracts. 1675-1680.

OKSANEN-SA“ RELA“, K. AND TIMONEN, P. 2004. Making sense of walking practice-the case of Nordic walking. EASST Session S 106 "The significance of socio-technical relations in the production and reproduction of normalised behaviour."

RECKWITZ, A. 2002. Toward a theory of social practices: a development in culturalist theorizing. Euro. J. Social Theory 5, 2, 243-263.

REITMAIER, T., BIDWELL, N. J., SIYA, M., MARSDEN, G., AND TUCKER, W. D. 2012. Communicating in designing an asynchronous oral repository for rural African communities. In Proceedings of the Conference of IST-Africa.

SENGERS, P. 2011. What I learned on Change Islands: Reflections on IT and pace of life. Interactions 182, 40-48.

SHOVE, E. 2003. Comfort, Cleanliness and Convenience: The Social Organisation of Normality. Berg Publishers, Oxford, UK.

SHOVE, E. AND PANTZAR, M. 2005. Consumers, producers and practices: understanding the invention and reinvention of Nordic walking. J. Consumer Culture 51, 43-64.

STATISTICS SOUTH AFRICA. 2010. http://www.statssa.gov.za/.

STENGERS, I. 2000. The Invention of Modern Science. University of Minnesota Press.

STRENGERS, Y. 2008. Smart metering demand management programs: challenging the comfort and cleanliness habitus of households. In Proceedings of the Australian Conference on Computer-Human Interaction (OZCHI'O8). 9-16.

STRENGERS, Y. 2011. Negotiating everyday life: The role of energy feedback. J. Consumer Culture 11, 3, 319-338.

TACCHI, J., SLATER, D., AND LEWIS, P. 2003. Evaluating community based media initiatives: an ethnographic action research approach. In Proceedings of the Annual International Conference on Information Technology for Development.

TAYLOR, A. 2011. Out there. In Proceedings of the SIGCHI Conference on Human Factors in Computing Systems. 685-694.

TUCKER, W. D., BLAKE, E. H., MARSDEN, G., PEARSON, M., AND WESTERVELD, R. 2007. Reflection on three years of rural wireless Internet Protocol communication. In Proceedings of the Southern African Telecommunication Networks and Applications Conference. 452-457.

WATKINS, T. AND TACCHI, J. 2008. Finding a voice through content creation. In Participatory Content Creation for Development: Principles and Practices, 13-20.

WINTHER, T. 2012. Electricity theft as a relational issue: a comparative look at Zanzibar, Tanzania, and the Sunderban Islands, India. Energy for Sustainable Development 161, 111-119.

WORLD BANK. 2010. Poverty: Statistics and Indicators. http://web.worldbank.org. 
WYCHE, S. AND MURPHY, L. L. 2012. "Dead China-make" phones off the grid: investigating and designing bile phone use in rural Africa. In Proceedings of the Designing Interactive Systems Conference. 186-195. 